\title{
Study on the Control Strategy of Shifting Time Involving Multigroup Clutches
}

\author{
Zhen Zhu, ${ }^{1}$ Xiang Gao, ${ }^{1}$ Daoyuan Pan, ${ }^{2}$ Yu Zhu, ${ }^{3}$ and Leilei Cao ${ }^{1}$ \\ ${ }^{1}$ School of Automotive and Traffic Engineering, Jiangsu University, Zhenjiang 212013, China \\ ${ }^{2}$ School of Mechanical and Automotive Engineering, Anhui Polytechnic University, Wuhu 241000, China \\ ${ }^{3}$ Axle Branch Company, IVECO Co. Ltd., Nanjing 212028, China \\ Correspondence should be addressed to Xiang Gao; xianggaojs@163.com
}

Received 22 August 2015; Revised 17 November 2015; Accepted 18 November 2015

Academic Editor: Weiguo Xia

Copyright (C) 2016 Zhen Zhu et al. This is an open access article distributed under the Creative Commons Attribution License, which permits unrestricted use, distribution, and reproduction in any medium, provided the original work is properly cited.

\begin{abstract}
This paper focuses on the control strategy of shifting time involving multigroup clutches for a hydromechanical continuously variable transmission (HMCVT). The dynamic analyses of mathematical models are presented in this paper, and the simulation models are used to study the control strategy of HMCVT. Simulations are performed in Simulation $X$ platform to investigate the shifting time of clutches under different operating conditions. On this basis, simulation analysis and test verification of two typical conditions, which play the decisive roles for the shifting quality, are carried out. The results show that there are differences in the shifting time of the two typical conditions. In the shifting process from the negative transmission of hydromechanical ranges to the positive transmission of hydromechanical ranges, the control strategy based on the shifting time is switching the clutches of shifting mechanism firstly and then disengaging a group of clutches of planetary gear mechanism and engaging another group of the clutches of planetary gear mechanism lastly. In the shifting process from the hydraulic range to the hydromechanical range, the control strategy based on the shifting time is switching the clutches of hydraulic shifting mechanism and planetary gear mechanism at first and then engaging the clutch of shifting mechanism.
\end{abstract}

\section{Introduction}

Hydromechanical continuously variable transmission (HMCVT) is a compound stepless variable speed device, which is mainly composed of the hydraulic speed regulation mechanism and the mechanical speed variation mechanism $[1,2]$. Because of the stepless speed change of hydraulic transmission and the high efficiency of mechanical transmission, HMCVT has attracted more and more attention in recent years [3-6]. However, the research on HMCVT focuses on the construction design and performance study for a long time [7-10]. With the increasing requirements of vehicle ride comfort, the dynamic properties research on shifting strategy becomes hot recently.

However, the research on shifting strategy is mainly focused on the physical parameters. For example, literature $[11,12]$ discussed the influence of hydraulic oil viscosity, hydraulic system working volume, and output shaft equivalent rotational inertia on the shifting quality; literature
$[11,13]$ studied the influence of length and radius of hydraulic pipelines and hydraulic oil bulk modulus on the shifting quality; literature $[14,15]$ analyzed the influence of engine rotational speed, load torque, main circuit pressure, and speed control valves flow rate on the shifting quality. The dynamic analysis and test of clutches are presented in literature [16-21].

The tests indicate that it has no obvious effect on the improvement of shifting quality by controlling the physical parameters only, especially to the multirange HMCVT, with multigroup clutches. The shift quality involving multigroup clutches is not only related to the design parameters of the clutch itself, but also affected by the shock of other clutches, which makes the modeling, simulation, and test more and more difficult. Tractors often work under extreme conditions, so the study on the shift shock is very important $[22,23]$. This paper focuses on the typical working conditions of shifting process and analyzes the shifting optimization strategy based on the shift time, and the simulation results should be verified 
TABLE 1: Components engagement conditions of HMCVT.

\begin{tabular}{|c|c|c|c|c|c|c|c|c|c|c|}
\hline \multirow{2}{*}{ Range } & \multicolumn{10}{|c|}{ Engagement conditions } \\
\hline & $S_{1}$ & $S_{2}$ & $C_{1}$ & $C_{2}$ & $C_{3}$ & $C_{4}$ & $C_{5}$ & $C_{6}$ & $C_{7}$ & $C_{8}$ \\
\hline \multicolumn{11}{|l|}{ Forward } \\
\hline $\mathrm{F}_{3}(\mathrm{~N})$ & On & & On & & On & & & & On & \\
\hline $\mathrm{F}_{3}(\mathrm{P})$ & On & & & On & & On & & & On & \\
\hline $\mathrm{F}_{2}(\mathrm{~N})$ & On & & On & & On & & & On & & \\
\hline $\mathrm{F}_{2}(\mathrm{P})$ & On & & & On & & On & & On & & \\
\hline $\mathrm{F}_{1}(\mathrm{~N})$ & On & & On & & On & & On & & & \\
\hline $\mathrm{F}_{1}(\mathrm{P})$ & On & & & On & & On & On & & & \\
\hline $\mathrm{F}(\mathrm{H})$ & On & & & & & & & & & On \\
\hline \multicolumn{11}{|l|}{ Reverse } \\
\hline $\mathrm{R}(\mathrm{H})$ & & On & & & & & & & & On \\
\hline $\mathrm{R}_{1}(\mathrm{P})$ & & On & & On & & On & & On & & \\
\hline $\mathrm{R}_{1}(\mathrm{~N})$ & & On & On & & On & & & On & & \\
\hline
\end{tabular}

Note: $\mathrm{F} / \mathrm{R}$ - forward/reverse; $\mathrm{P} / \mathrm{N}$ - positive/negative transmission of hydromechanical ranges; $\mathrm{H}-$ transmission of hydraulic range.

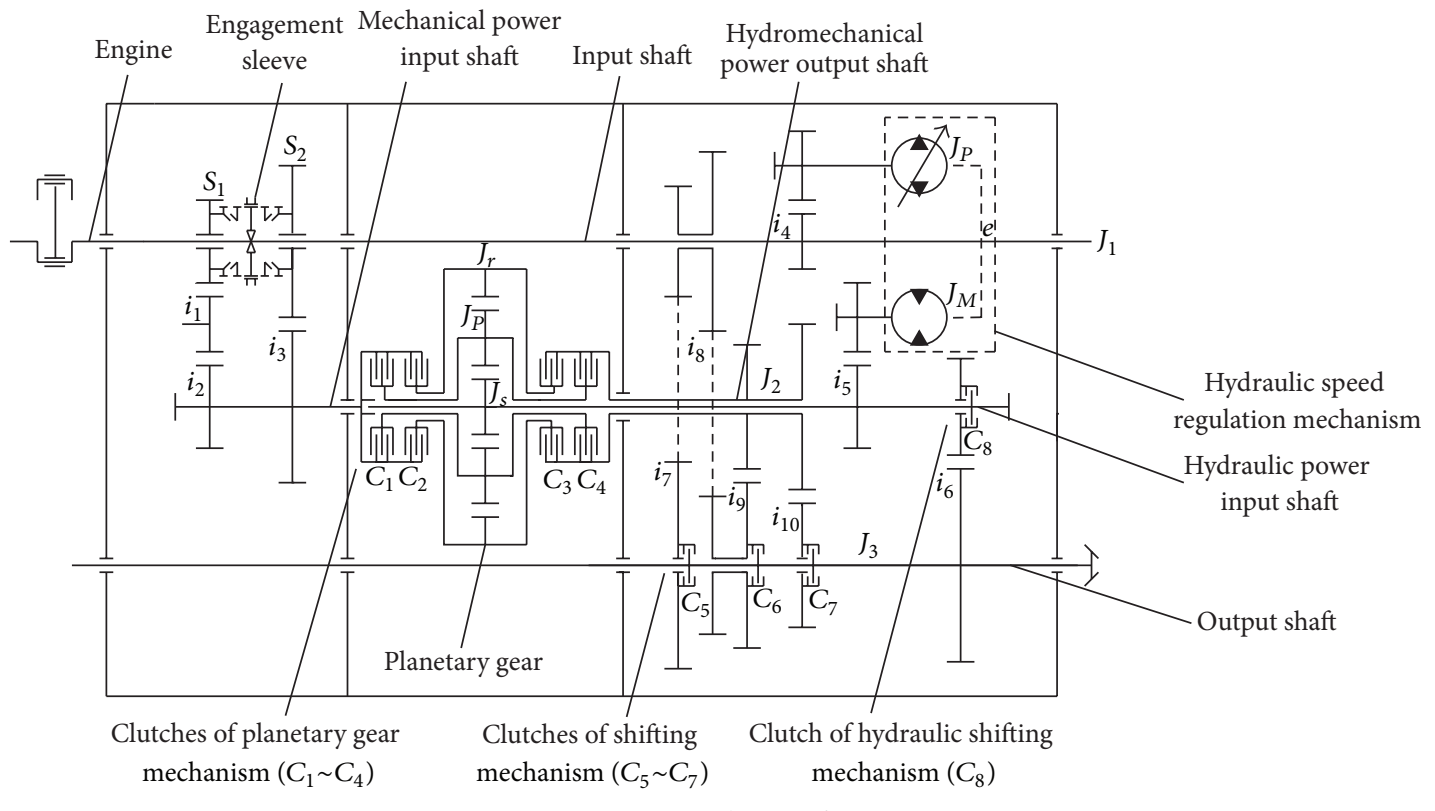

FIgURE 1: Design scheme of HMCVT.

through tests. The results show that the shifting quality can be improved greatly by optimizing the shifting time of HMCVT involving multigroup clutches, and the typical working conditions decide the shifting quality of the whole continuous shifting process.

\section{Dynamic Model of HMCVT}

2.1. Design Scheme of HMCVT. The design scheme of HMCVT is shown in Figure 1. The input shaft is connected with the engine via the universal joint. The output shaft is connected with the driving wheel via driving bridge. The single planetary gear is connected with the mechanical power input shaft and the hydromechanical power output shaft via clutches of planetary gear mechanism $\left(C_{1} \sim C_{4}\right)$. The hydromechanical power output shaft is connected with the output shaft via clutches of shifting mechanism $\left(C_{5} \sim C_{7}\right)$. The clutches of hydraulic shifting mechanism $\left(C_{8}\right)$ realize the transition from the stationary state to the hydromechanical range. Engagement sleeve manipulates the driving direction [24].

Table 1 shows the components engagement conditions of HMCVT.

Figure 2 presents the relationship curves between the tractor speed and the displacement ratio, which can show the stepless speed regulation characteristics of HMCVT.

2.2. Dynamic Analysis of HMCVT. Multirange HMCVT for tractors is a complicated transmission system, which can be simplified as shafting, planetary gear mechanism, hydraulic speed regulation mechanism, variable displacement pumpfixed displacement motor system, and wet clutches control system $[25,26]$. 


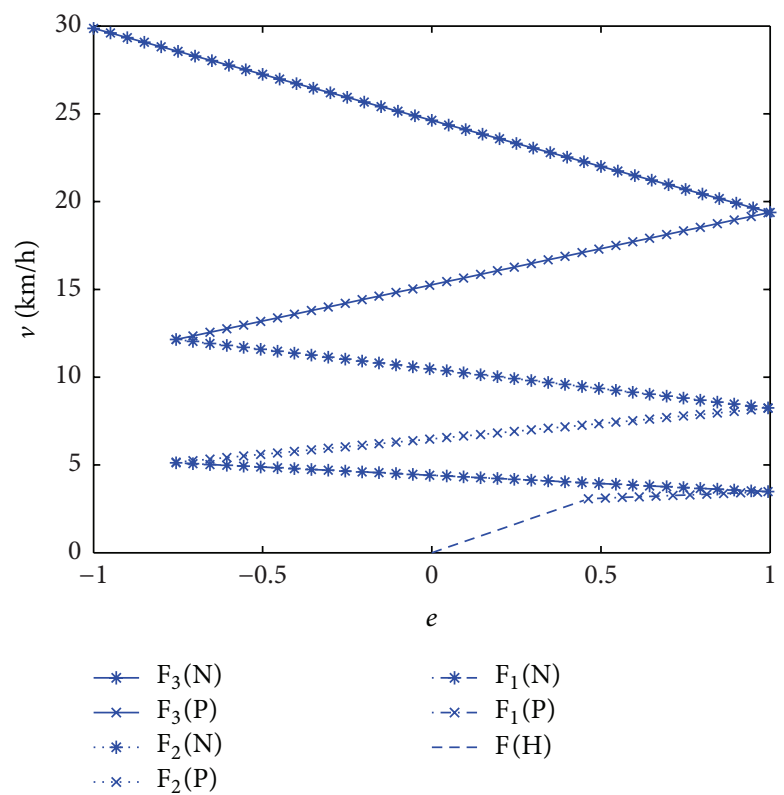

FIGURE 2: Stepless speed regulation characteristic curves of HMCVT.

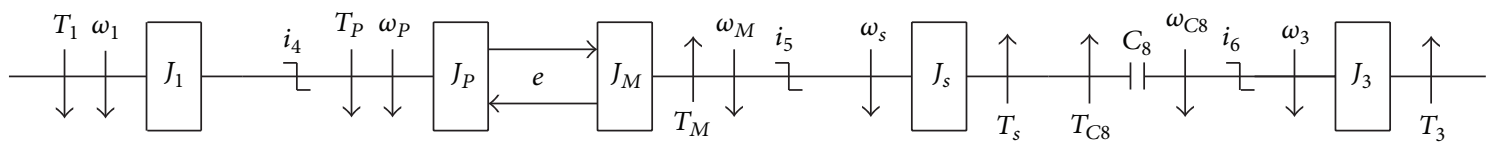

FIgURE 3: Equivalent dynamic model of the hydrostatic drive system.

2.2.1. Shafting. The transmission system of the design scheme of HMCVT can be divided into hydrostatic drive system and hydromechanical transmission system according to the transmission type. The operation state of shafting includes single-shaft rotation and multishaft rotation according to the engagement conditions of wet clutches.

Equivalent dynamic model of the hydrostatic drive system is shown in Figure 3.

(1) Single-Shaft Rotation of Hydrostatic Drive System. The dynamic equation can be expressed as

$$
\begin{aligned}
& J_{1} \frac{d \omega_{1}}{d t}=T_{1}-\frac{T_{P}}{i_{4}}, \\
& J_{3} \frac{d \omega_{3}}{d t}=\left(T_{s}+T_{C 8}\right) i_{6}-T_{3}, \\
& J_{s} \frac{d \omega_{s}}{d t}=T_{M} i_{5}-T_{s} .
\end{aligned}
$$

(2) Multishaft Rotation of Hydrostatic Drive System. The dynamic equation can be expressed as

$$
\begin{aligned}
J_{E} \frac{d \omega_{E}}{d t} & =T_{\mathrm{EP}}-T_{\mathrm{EN}}, \\
\omega_{E} & =\omega_{s}, \\
\omega_{3} & =\frac{\omega_{s}}{i_{6}},
\end{aligned}
$$

$$
\begin{aligned}
J_{E} & =J_{s}+\frac{J_{3}}{i_{6}{ }^{2}}, \\
T_{\mathrm{EP}} & =T_{M} i_{5}, \\
T_{\mathrm{EN}} & =T_{s}+T_{C 8}+\frac{T_{3}}{i_{6}} .
\end{aligned}
$$

Equivalent dynamic model of the hydromechanical transmission system is shown in Figure 4.

(3) Single-Shaft Rotation of Hydromechanical Transmission System. The dynamic equation can be expressed as

$$
\begin{aligned}
& J_{1} \frac{d \omega_{1}}{d t}=T_{1}-\frac{T_{P}}{i_{4}}-\frac{T_{C 1}}{i_{1} i_{2}}-\frac{T_{C 2}}{i_{1} i_{2}}, \\
& J_{2} \frac{d \omega_{2}}{d t}=T_{C 3}+T_{C 4}-\frac{T_{C 5}}{i_{7} i_{8} i_{9}}-\frac{T_{C 6}}{i_{9}}-\frac{T_{C 7}}{i_{10}}, \\
& J_{3} \frac{d \omega_{3}}{d t}=T_{C 5}+T_{C 6}+T_{C 7}-T_{3}, \\
& J_{s} \frac{d \omega_{s}}{d t}=T_{M} i_{5}-T_{s}, \\
& J_{c} \frac{d \omega_{c}}{d t}=T_{C 1}+T_{c}-T_{C 4}, \\
& J_{r} \frac{d \omega_{r}}{d t}=T_{C 2}-T_{r}-T_{C 3} .
\end{aligned}
$$




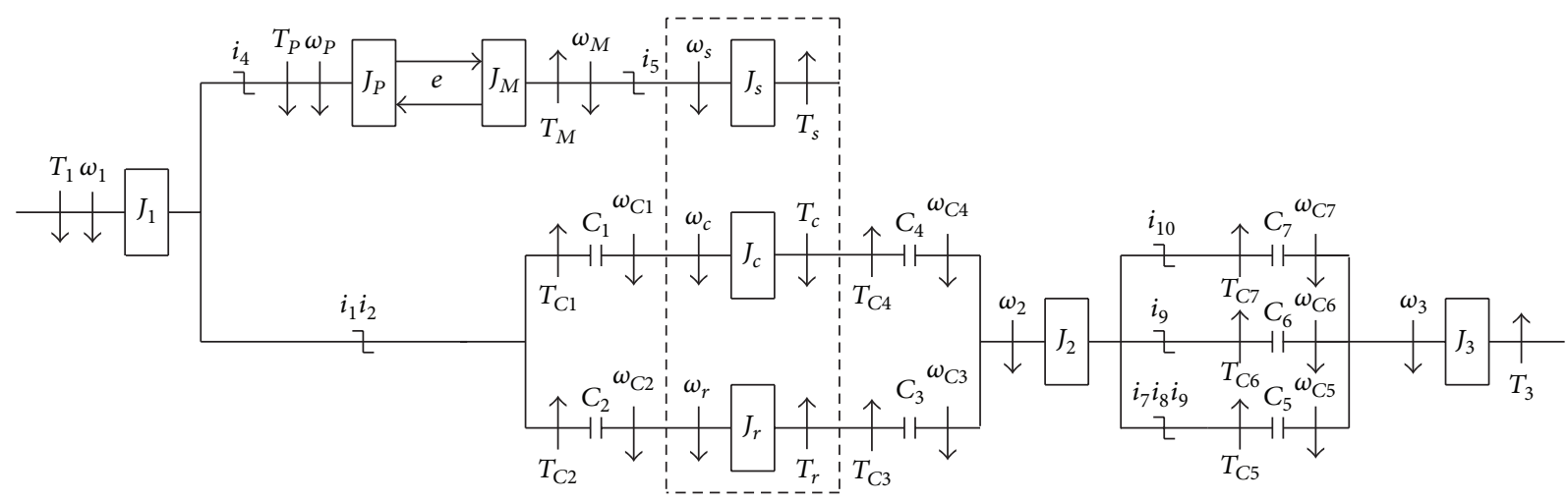

FIgURE 4: Equivalent dynamic model of the hydromechanical transmission system.

(4) Multishaft Rotation of Hydromechanical Transmission System. The clutches should be divided into 4 groups: group 1 $\left(C_{1}, C_{3}\right)$, group $2\left(C_{2}, C_{4}\right)$, group $3\left(C_{5} \sim C_{7}\right)$, and group $4\left(C_{8}\right)$, and each clutch can be regarded as 3 conditions: disengaging condition, switching condition, and engaging condition. So there are $3 \times 3 \times 4+1=37$ conditions of clutches during the whole shifting process.

2.2.2. Planetary Gear Mechanism. Kinematics equation and kinetic equation of planetary gear mechanism can be expressed as [27, 28]

$$
\begin{aligned}
\omega_{s}+k \omega_{r}-(k+1) \omega_{c} & =0 \\
T_{s}: T_{r}: T_{c} & =1: k:(k+1) .
\end{aligned}
$$

2.2.3. Hydraulic Speed Regulation Mechanism. Big horsepower agricultural vehicles demand high standards of system stability. Test results show that pump control motor system with the electrohydraulic proportional closed-loop circuit reduced dynamic response time of hydraulic system and eliminated the overshoot to some intent, which can automatically adjust the external load disturbance and gradually obtain stable performance $[29,30]$. Figure 5 presents the pump control motor system with the electrohydraulic proportional closed-loop circuit.

Hydraulic speed regulation mechanism is composed by four parts: variable displacement pump-fixed displacement motor system, control system of pump, valve assembly, and slippage and washing system $[31,32]$. The simplified dynamic model of hydraulic speed regulation mechanism is shown in Figure 6.

The dynamic equation of hydraulic speed regulation mechanism can be expressed as

$$
\begin{gathered}
\frac{V}{\beta_{e}} \frac{d p_{h}}{d t}=e D_{M \max } \omega_{P}-D_{M \max } \omega_{M}, \\
J_{P} \frac{d \omega_{P}}{d t}=T_{P}-e D_{M \max }\left(p_{h}-p_{l}\right), \\
J_{M} \frac{d \omega_{M}}{d t}=T_{M}-D_{M \max }\left(p_{h}-p_{l}\right) .
\end{gathered}
$$

2.2.4. Dynamic Model of Switching Process Involving Two Clutches. The disengagement and engagement of wet clutches are controlled by the oil pressure. The external hub and gears are connected by bolts, while the internal hub and shaft are connected by the double flat key. The sliding bearing and the needle bearing share the cooling and lubricating system, which adopts the pressure lubrication, while other gears in the transmission system adopt the splash lubrication. The hydraulic system of clutches is presented in Figure 7.

The switching process involving two clutches experiences 4 stages: before switching stage, torque phase, inertial phase, and after switching stage[33]. The dynamic model of shifting process is shown in Figure 8.

(1) Before switching $\left(C_{1}^{\prime}\right.$ : engagement, $C_{2}^{\prime}$ : disengagement) stage is as follows:

$$
\begin{aligned}
& \omega_{z 1}^{\prime}=\omega_{1}^{\prime} i_{1}^{\prime}, \\
& \omega_{c 1}^{\prime}=\omega_{z 1}^{\prime}, \\
& \omega_{c 2}^{\prime}=\omega_{1}^{\prime} i_{2}^{\prime}, \\
& \omega_{z 2}^{\prime}=\omega_{2}^{\prime} i_{2}^{\prime}, \\
& T_{C 1}^{\prime}=\frac{T_{1}^{\prime}}{i_{1}^{\prime}} \\
& T_{C 2}^{\prime}=0 .
\end{aligned}
$$

(2) Torque phase $\left(C_{1}^{\prime}\right.$ : oil drainage (engagement), $C_{2}^{\prime}$ : oil filling (slipping)) is as follows:

$$
\begin{aligned}
& \omega_{z 1}^{\prime}=\omega_{1}^{\prime} i_{1}^{\prime}, \\
& \omega_{c 1}^{\prime}=\omega_{z 1}^{\prime}, \\
& \omega_{c 2}^{\prime}=\omega_{1}^{\prime} i_{2}^{\prime}, \\
& \omega_{z 2}^{\prime}=\omega_{2}^{\prime} i_{2}^{\prime}, \\
& T_{C 1}^{\prime}=\frac{T_{1}^{\prime}}{i_{1}^{\prime}},
\end{aligned}
$$




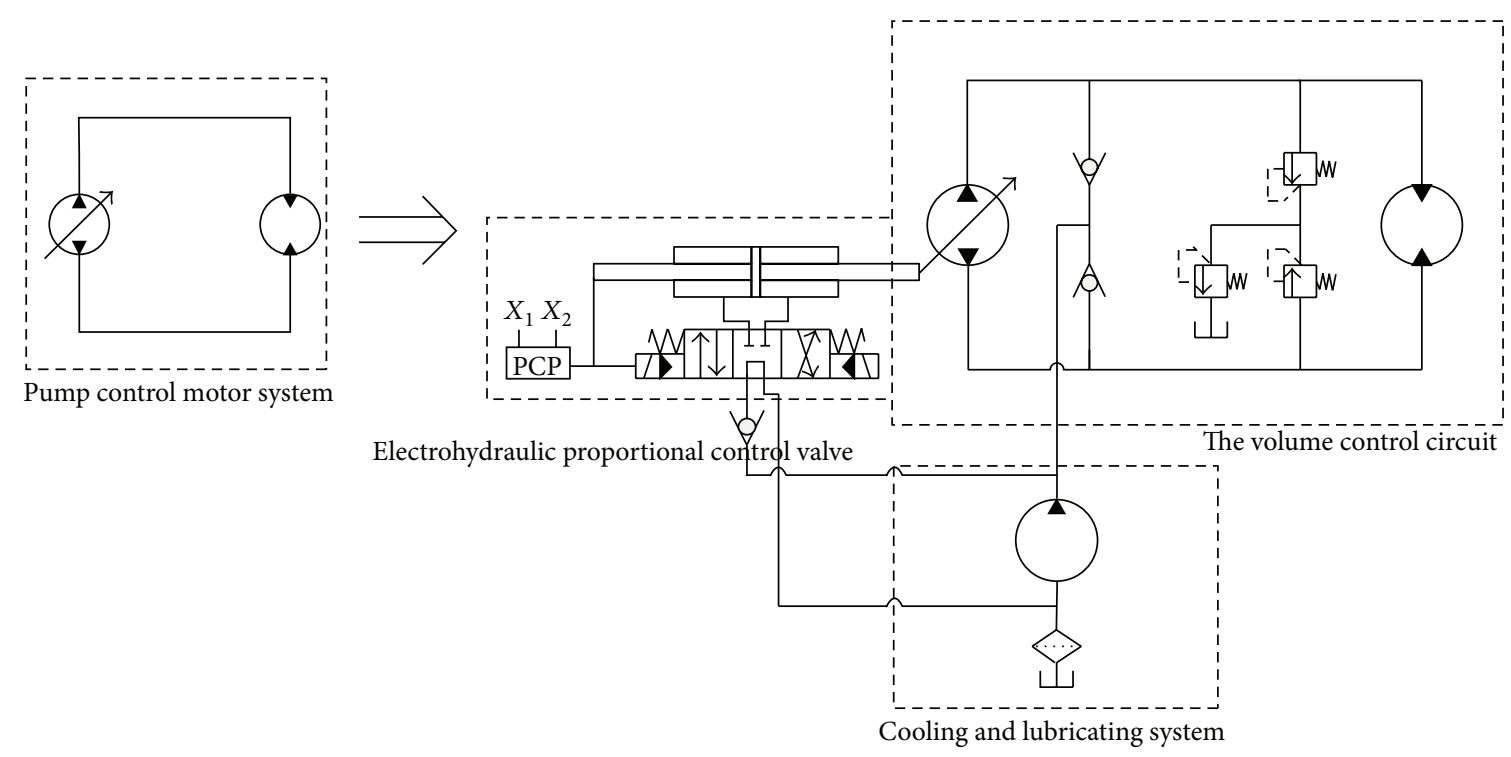

Figure 5: Pump control motor system with the electrohydraulic proportional closed-loop circuit.

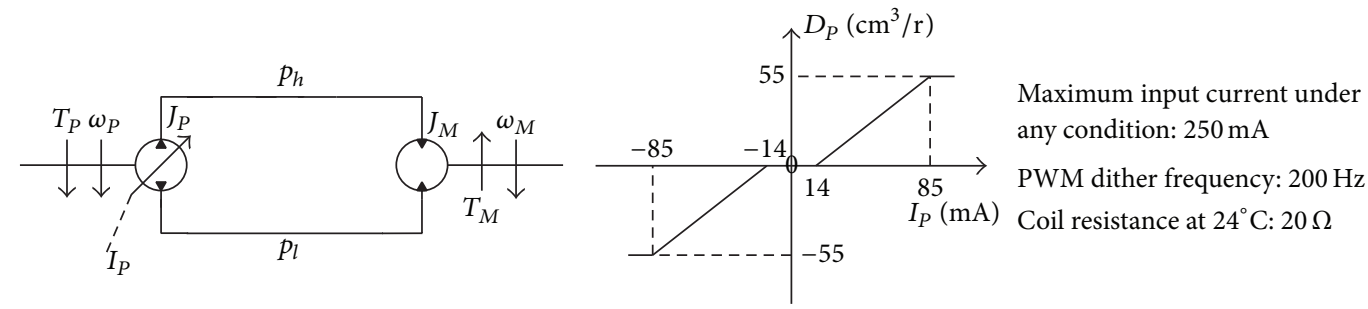

FIGURE 6: Simplified dynamic model of the hydraulic speed regulation mechanism.

$$
\begin{aligned}
T_{C 2}^{\prime} & =\frac{2}{3} \pi\left(R_{C 2^{\prime} 1}^{3}-R_{C 2^{\prime} 2}{ }^{3}\right) Z_{C 2^{\prime}} \operatorname{sign}\left(\omega_{z 2}^{\prime}-\omega_{c 2}^{\prime}\right) \\
& \cdot \mu_{r C 2}\left(\omega_{z 2}^{\prime}-\omega_{c 2}^{\prime}\right) p_{C 2^{\prime}}(t)
\end{aligned}
$$

(3) Inertial phase $\left(C_{1}^{\prime}\right.$ : slipping, $C_{2}^{\prime}$ : slipping) is as follows:

$$
\begin{aligned}
\omega_{z 1}^{\prime} & =\omega_{1}^{\prime} i_{1}^{\prime}, \\
\omega_{z 2}^{\prime} & =\omega_{2}^{\prime} i_{2}^{\prime}, \\
\omega_{c 1}^{\prime} & \neq \omega_{z 1}^{\prime}, \\
\omega_{c 2}^{\prime} & \neq \omega_{z 2}^{\prime}, \\
T_{C 1}^{\prime} & =\frac{2}{3} \pi\left(R_{C 1^{\prime} 1}^{3}-R_{C 1^{\prime} 2}^{3}\right) Z_{C 1^{\prime}} \operatorname{sign}\left(\omega_{z 1}^{\prime}-\omega_{c 1}^{\prime}\right) \\
\cdot & \mu_{r C 1}\left(\omega_{z 1}^{\prime}-\omega_{c 1}^{\prime}\right) p_{C 1^{\prime}}(t), \\
T_{C 2}^{\prime} & =\frac{2}{3} \pi\left(R_{C 2^{\prime} 1}^{3}-R_{C 2^{\prime} 2}{ }^{3}\right) Z_{C 2^{\prime}} \operatorname{sign}\left(\omega_{z 2}^{\prime}-\omega_{c 2}^{\prime}\right) \\
\cdot & \mu_{r C 2}\left(\omega_{z 2}^{\prime}-\omega_{c 2}^{\prime}\right) p_{C 2^{\prime}}(t) .
\end{aligned}
$$

2.2.5. Dynamic Model of Pressure Control Module. Pressure control module of clutch system can be simplified as

$$
\begin{array}{r}
p_{C i}^{\prime}(t)=\int_{t_{1}^{\prime}-\tau^{\prime}}^{t_{2}^{\prime}-\tau^{\prime}}\left\{C_{C i}^{\prime}(t) \kappa_{i \mathrm{on}}^{\prime}+\left[1-C_{C i}^{\prime}(t)\right] \kappa_{i \mathrm{off}}^{\prime}\right\} d t \\
p_{C i}^{\prime}(t) \in\left[0, p_{C i \max }^{\prime}\right] .
\end{array}
$$




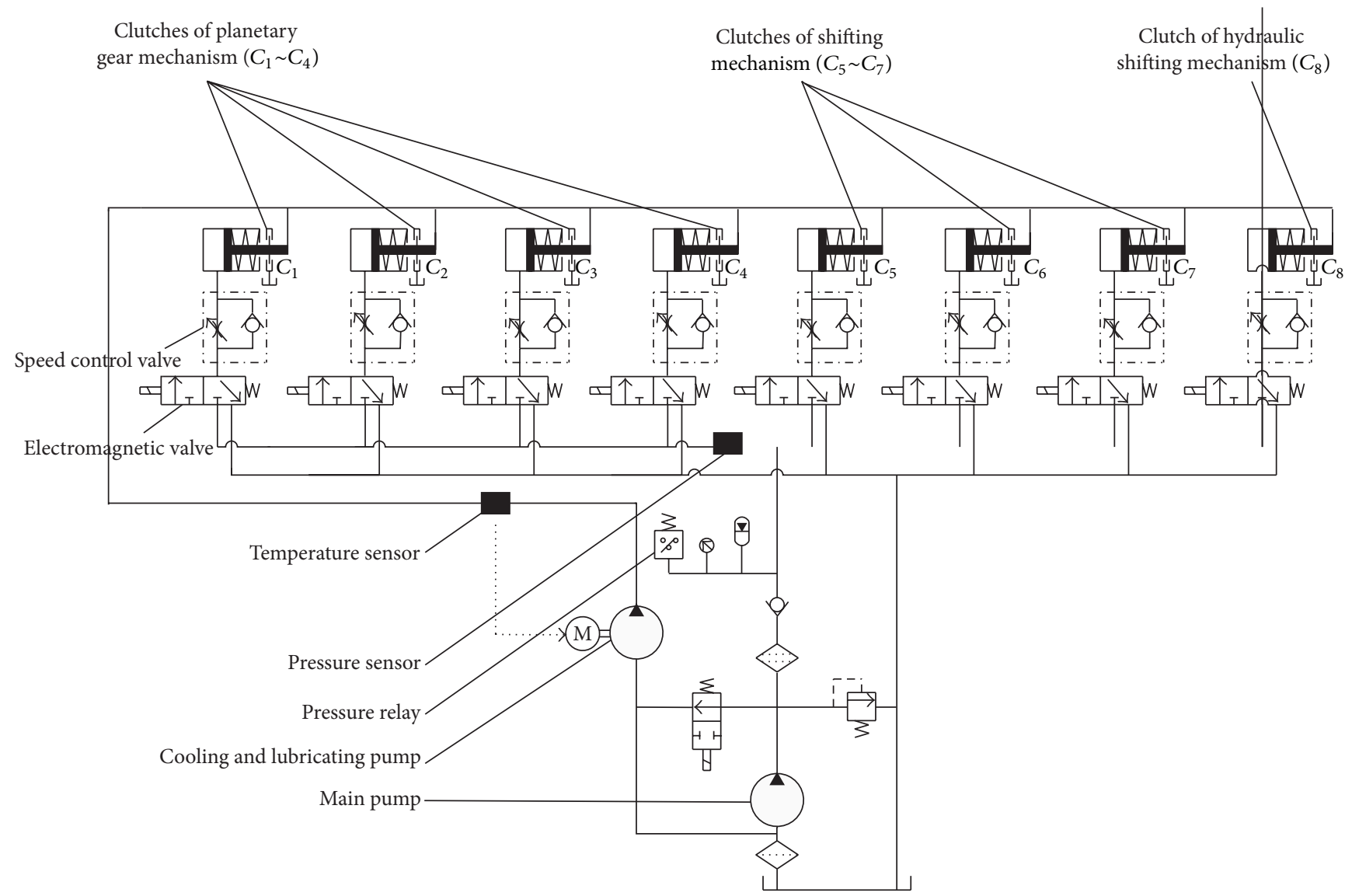

FIGURE 7: The hydraulic system of clutches.

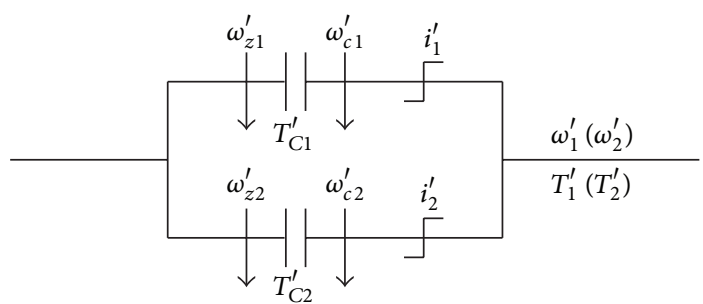

FIGURE 8: Dynamic model of switching process involving two clutches.

2.3. Evaluation Indices of Shifting Quality. Output shaft speed drop amplitude, output shaft dynamic load coefficient, maximum impact, and shifting time are selected as the evaluation index of shifting quality.

(1) Output Shaft Speed Drop Amplitude. Output shaft speed drop amplitude embodies the rotational speed fluctuation during shifting, which can be expressed as

$$
\delta=\frac{\left|\bar{n}_{o}-n_{o \min }\right|}{\bar{n}_{o}} .
$$

(2) Output Shaft Dynamic Load Coefficient. Output shaft dynamic load coefficient embodies the torque fluctuation during shifting, which can be expressed as

$$
\gamma=\frac{T_{o \max }}{\bar{T}_{o}}
$$

(3) Output Shaft/Hydromechanical Power Output Shaft Maximum Impact. Maximum impact embodies the vibration and impact of shaft. Output shaft maximum impact and hydromechanical power output shaft maximum impact are used to analyze the different action of clutches during shifting. Output shaft maximum impact can be expressed as

$$
j=\frac{d^{2} v}{d t^{2}} .
$$

(4) Shifting Time. As the slipping friction work of wet clutch is difficult to measure, this paper holds that the shifting is 


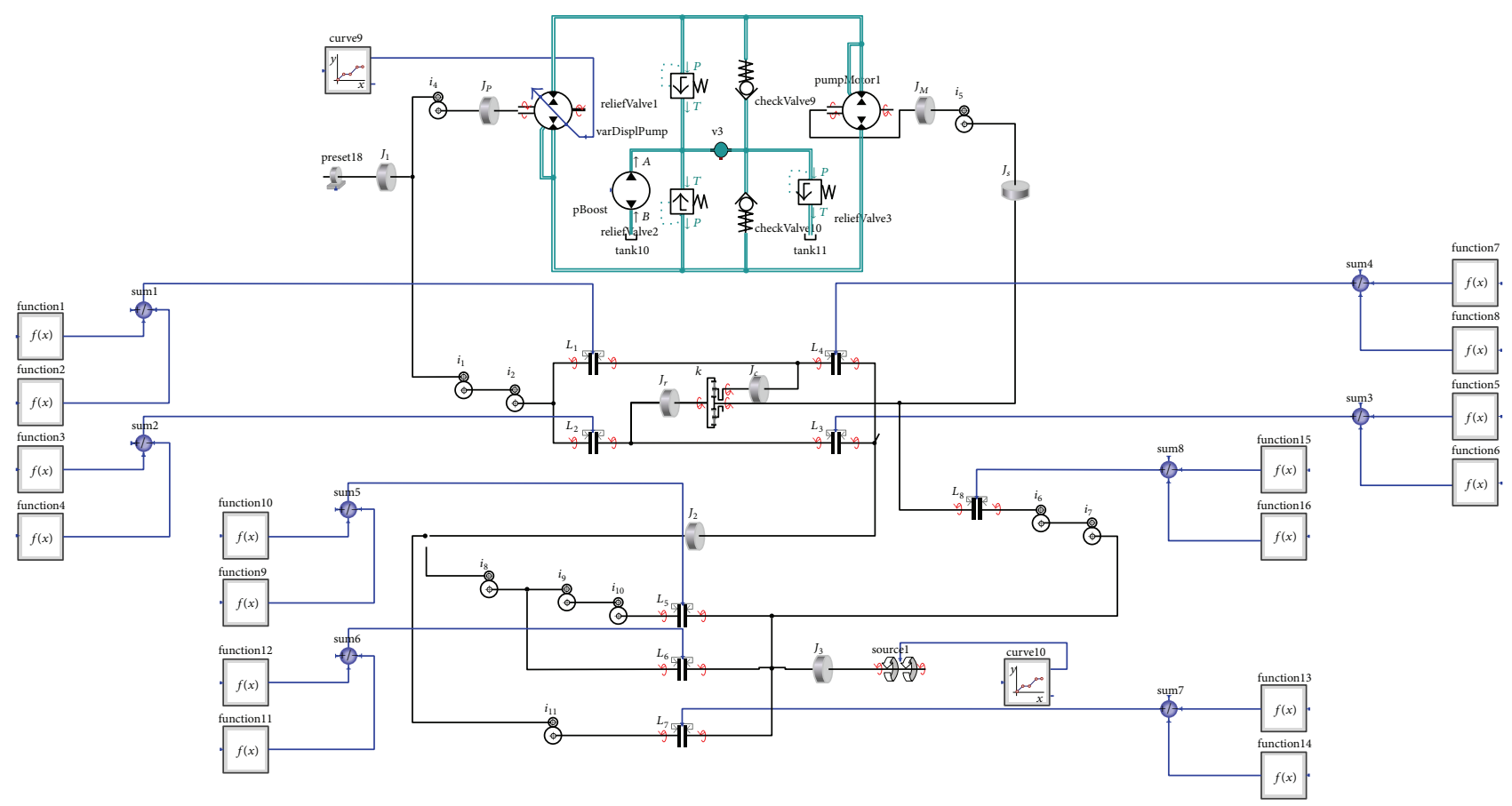

FIGURE 9: Simulation model of HMCVT based on Simulation $X$.

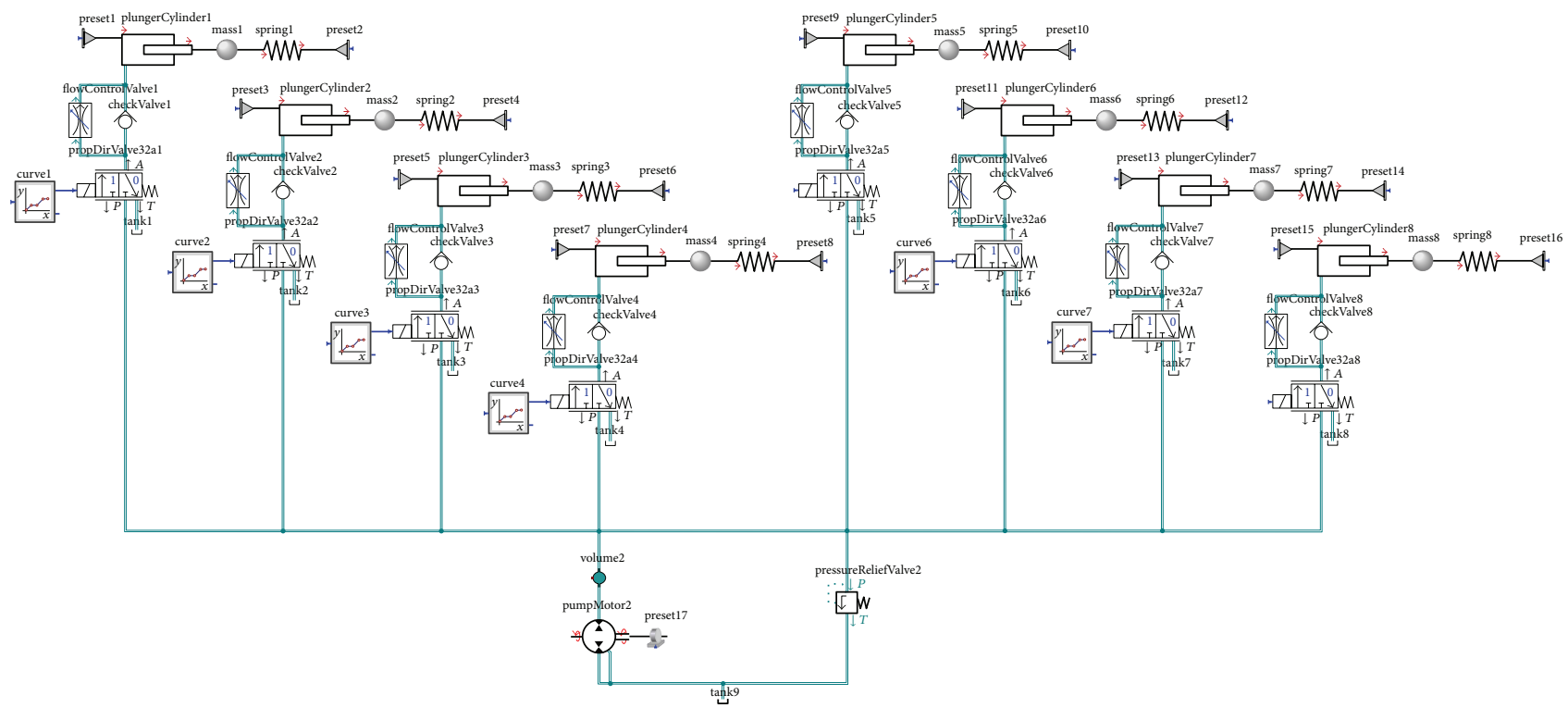

FIGURE 10: Hydraulic control module of clutch system.

finished when the output shaft rotational speed reaches $99 \%$ of the stable rotational speed.

\section{Simulation Analysis for Shifting Process}

3.1. Simulation Model of HMCVT. According to the design scheme of HMCVT in Figure 1, the simulation model of HMCVT based on Simulation $X$ is shown in Figure 9.

The model of HMCVT includes 5 modules: power module, load module, hydraulic speed regulation module, mechanical transmission module, and hydraulic control module of clutch system [34]. Among them, the hydraulic control module of clutch system is the core module for the study of shifting control strategy, which is shown in Figure 10.

3.2. Continuous Shifting Process of HMCVT. According to the simulation model above, control of the conditions of clutches and displacement ratio of hydraulic speed regulation mechanism at every $10 \mathrm{~s}$, the simulation condition can be expressed as follows: engine rotational speed is $1500 \mathrm{r} / \mathrm{min}$; load torque 

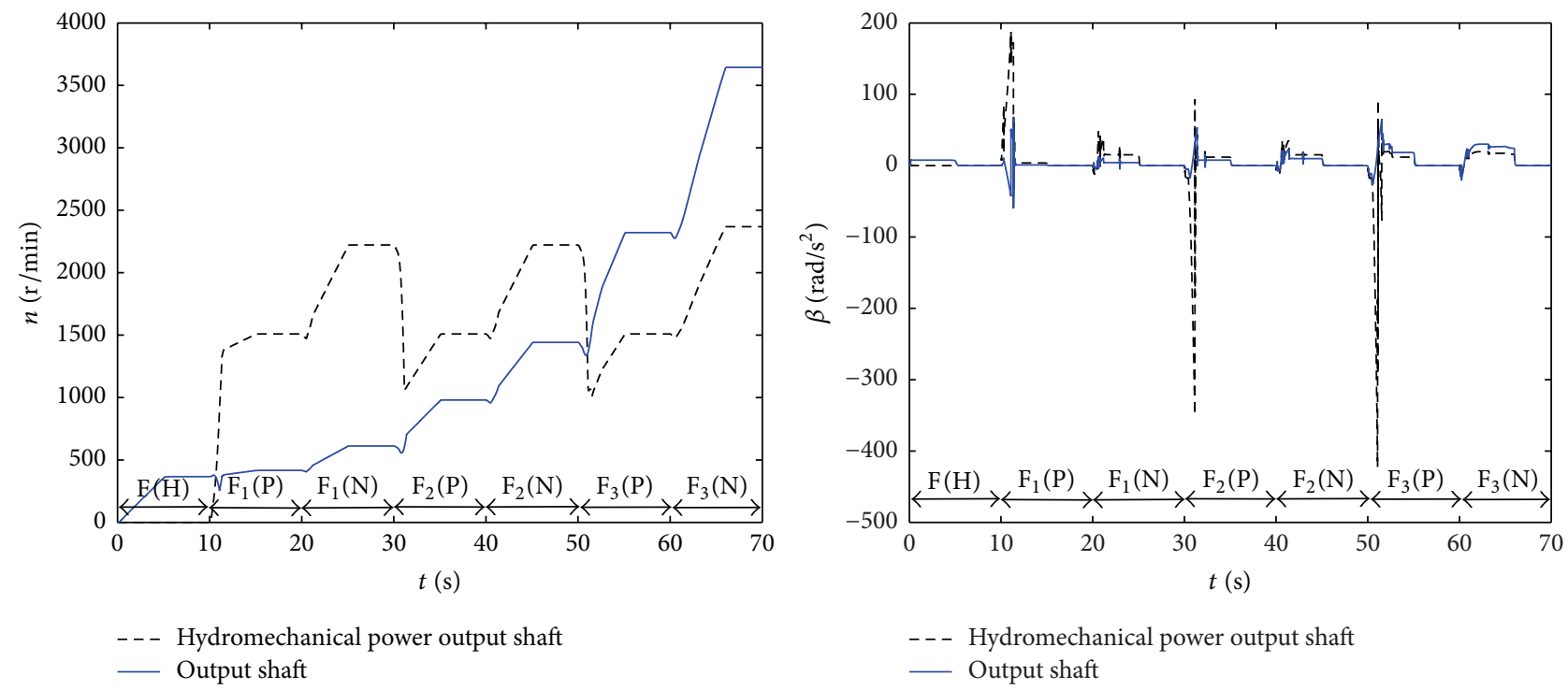

FIGURE 11: Simulation curves of continuous shifting process.

TABLE 2: Switching conditions of clutches $\left(\mathrm{F}_{2}(\mathrm{~N}) \rightarrow \mathrm{F}_{3}(\mathrm{P})\right)$.

\begin{tabular}{lcccc}
\hline & \multicolumn{2}{c}{ Before switching } & \multicolumn{2}{c}{ After switching } \\
& Engagement & Disengagement & Engagement & $C_{1}, C_{3}$ \\
\hline Group 1 & $C_{1}, C_{3}$ & $C_{2}, C_{4}$ & $C_{4}$ & $C_{6}$ \\
Group 2 & & $C_{7}$ & $C_{7}$ & Disengagement \\
Group 3 & $C_{6}$ &
\end{tabular}

is $150 \mathrm{Nm}$; main circuit pressure is 50 bar; speed valve flow rate is $5 \mathrm{~L} / \mathrm{min}$. The simulation curves of continuous shifting process are shown in Figure 11.

Rotational speed curves embody the speed change of shafts, and angular acceleration curves embody the torque fluctuation of shafts, both of which can reflect the shifting quality well. We can include that the shifting process from $\mathrm{F}(\mathrm{H})$ to $\mathrm{F}_{1}(\mathrm{P})$ and the process from $\mathrm{F}_{j}(\mathrm{~N})$ to $\mathrm{F}_{j+1}(\mathrm{P})(j=$ $1,2)$, which play decisive roles of improving the shifting quality during the continuous shifting process, are the typical working conditions.

Impact is caused by the switching time difference during shifting. Load torque leads to a rapid decrease of output shaft rotational speed, and output shaft rotational speed will reach the minimum valve, when its transmission torque realizes the balance between clutch and load. So it is a new thought to control the switching time of clutches to improve the shifting quality. This paper takes the shifting process from $\mathrm{F}_{2}(\mathrm{~N})$ to $\mathrm{F}_{3}(\mathrm{P})$ and the process from $\mathrm{F}(\mathrm{H})$ to $\mathrm{F}_{1}(\mathrm{P})$, for example, to study the control strategy based on the shifting time.

3.3. Simulation Analysis of Shifting Strategy $\left(F_{2}(N) \rightarrow F_{3}(P)\right)$. There are 6 clutches that involve the shifting process from $\mathrm{F}_{2}(\mathrm{~N})$ to $\mathrm{F}_{3}(\mathrm{P})$, so the clutches should be divided into 3 groups, which are shown in Table 2.

The simulation condition can be expressed as follows: engine rotational speed is $1200 \mathrm{r} / \mathrm{min}$; load torque is $100 \mathrm{Nm}$; main circuit pressure is $40 \mathrm{bar}$; speed valve flow rate is $4 \mathrm{~L} / \mathrm{min}$.
3.3.1. Switching Strategy of Clutches among 3 Groups. The longer the switching time is, the larger the shafts speed fluctuation amplitude is; the shorter the switching time is, the tighter the clutches engagement conditions are. In view of this, the switching time of clutches in the same group should not show distinctive difference, while the shifting time difference exists in the different groups of clutches.

Range analysis tables of orthogonal test are shown in Tables 3-6. Output shaft speed drop amplitude, output shaft dynamic load coefficient, hydromechanical power output shaft maximum impact, and output shaft maximum impact are expected to be used as evaluation indices I, II, III, and IV. Factors A, B, and C, respectively, represent the first, the second, and the third group of clutches, and Factor D is the blank column. Levels 1, 2, and 3, respectively, represent the different switching time of clutches $(9.50,10.00$, and $10.50 \mathrm{~s})$.

Evaluation indices III and IV embody the degree of shock, and hydromechanical power output shaft maximum impact is mainly determined by the clutches of planetary gear mechanism, while output shaft maximum impact is mainly determined by the clutches of shifting mechanism. Impact is proportional to the second-order derivative of output shaft rotational speed, dynamic load coefficient is proportional to the first-order derivative of output shaft rotational speed, and speed drop amplitude is proportional to the zero-order derivative of output shaft rotational speed, so the evaluation index ranking should be considered as: III = IV > II > I. Besides, each evaluation index should be in the reasonable range. 
TABLE 3: Range analysis table of output shaft speed drop amplitude based on the shifting time.

\begin{tabular}{|c|c|c|c|c|c|c|}
\hline & Factor & $\mathrm{A}$ & $\mathrm{B}$ & $\mathrm{C}$ & $\mathrm{D}$ & \multirow{2}{*}{$\begin{array}{l}\text { Evaluation } \\
\text { index I }\end{array}$} \\
\hline & Column & 1 & 2 & 3 & 4 & \\
\hline \multirow{9}{*}{$\begin{array}{l}\text { Test } \\
\text { schemes }\end{array}$} & Test 1 & 1 & 1 & 1 & 1 & $18.28 \%$ \\
\hline & Test 2 & 1 & 2 & 2 & 2 & $22.62 \%$ \\
\hline & Test 3 & 1 & 3 & 3 & 3 & $27.20 \%$ \\
\hline & Test 4 & 2 & 1 & 2 & 3 & $28.74 \%$ \\
\hline & Test 5 & 2 & 2 & 3 & 1 & $34.11 \%$ \\
\hline & Test 6 & 2 & 3 & 1 & 2 & $4.91 \%$ \\
\hline & Test 7 & 3 & 1 & 3 & 2 & $47.41 \%$ \\
\hline & Test 8 & 3 & 2 & 1 & 3 & $7.04 \%$ \\
\hline & Test 9 & 3 & 3 & 2 & 1 & $8.64 \%$ \\
\hline \multirow{3}{*}{$\begin{array}{l}\text { Mean } \\
\text { number }\end{array}$} & $K_{1}$ & $22.70 \%$ & $31.48 \%$ & $10.08 \%$ & $20.34 \%$ & \multirow{3}{*}{$\begin{array}{l}K= \\
22.11 \%\end{array}$} \\
\hline & $K_{2}$ & $22.59 \%$ & $21.26 \%$ & $20.00 \%$ & $24.98 \%$ & \\
\hline & $K_{3}$ & $21.03 \%$ & $13.58 \%$ & $36.24 \%$ & $20.99 \%$ & \\
\hline Range & $R$ & $1.67 \%$ & $17.90 \%$ & $26.16 \%$ & $4.64 \%$ & \\
\hline \multicolumn{2}{|c|}{ Optimization scheme } & \multicolumn{5}{|c|}{$\mathrm{C}_{1} \mathrm{~B}_{3} \mathrm{~A}_{3}$} \\
\hline
\end{tabular}

TABLE 4: Range analysis table of output shaft dynamic load coefficient based on the shifting time.

\begin{tabular}{|c|c|c|c|c|c|c|}
\hline & Factor & $\mathrm{A}$ & B & $\mathrm{C}$ & $\mathrm{D}$ & \multirow{2}{*}{$\begin{array}{l}\text { Evaluation } \\
\text { index II }\end{array}$} \\
\hline & Column & 1 & 2 & 3 & 4 & \\
\hline \multirow{9}{*}{$\begin{array}{l}\text { Test } \\
\text { schemes }\end{array}$} & Test 1 & 1 & 1 & 1 & 1 & 2.47 \\
\hline & Test 2 & 1 & 2 & 2 & 2 & 2.55 \\
\hline & Test 3 & 1 & 3 & 3 & 3 & 2.64 \\
\hline & Test 4 & 2 & 1 & 2 & 3 & 2.70 \\
\hline & Test 5 & 2 & 2 & 3 & 1 & 2.77 \\
\hline & Test 6 & 2 & 3 & 1 & 2 & 2.37 \\
\hline & Test 7 & 3 & 1 & 3 & 2 & 2.95 \\
\hline & Test 8 & 3 & 2 & 1 & 3 & 2.52 \\
\hline & Test 9 & 3 & 3 & 2 & 1 & 2.01 \\
\hline \multirow{3}{*}{$\begin{array}{l}\text { Mean } \\
\text { number }\end{array}$} & $K_{1}$ & 2.55 & 2.71 & 2.45 & 2.42 & \multirow{3}{*}{$K=2.55$} \\
\hline & $K_{2}$ & 2.61 & 2.61 & 2.42 & 2.62 & \\
\hline & $K_{3}$ & 2.49 & 2.34 & 2.79 & 2.62 & \\
\hline Range & $R$ & 0.12 & 0.37 & 0.37 & 0.20 & \\
\hline \multicolumn{2}{|c|}{ Optimization scheme } & \multicolumn{5}{|c|}{$\mathrm{B}_{3} \mathrm{C}_{2}\left(\mathrm{C}_{2} \mathrm{~B}_{3}\right) \mathrm{A}_{3}$} \\
\hline
\end{tabular}

(1) Output Shaft Speed Drop Amplitude. The simulation parameters of output shaft speed drop amplitude are listed in Table 3 . The clutches in group 2 and group 3 have much more effect on evaluation index I than that in group 1 , so the scheme $\mathrm{C}_{1} \mathrm{~B}_{3} \mathrm{~A}_{3}$ can be replaced by the scheme $\mathrm{C}_{1} \mathrm{~B}_{3}$. The interval of index $\mathrm{I}$ is changed from $[-1.30 \%, 49.07 \%]$ (all schemes) to $[-1.30 \%, 5.01 \%]$ (scheme $\mathrm{C}_{1} \mathrm{~B}_{3}$ ). The minus implies the speed rise during shifting, which means the output shaft speed drop amplitude can reach 0 to obtain the optimal scheme.

(2) Output Shaft Dynamic Load Coefficient. The simulation parameters of output shaft dynamic load coefficient are listed in Table 4. The clutches in group 2 and group 3 have much more effect on evaluation index II than that in group 1 , so the scheme $B_{3} C_{2}\left(C_{2} B_{3}\right) A_{3}$ can be replaced by the scheme
$\mathrm{B}_{3} \mathrm{C}_{2}\left(\mathrm{C}_{2} \mathrm{~B}_{3}\right)$. The interval of index II is changed from [2.02, 3.08] (all schemes) to $[2.02,2.34]$ (scheme $B_{3} C_{2}\left(C_{2} B_{3}\right)$ ).

(3) Hydromechanical Power Output Shaft Maximum Impact. The simulation parameters of hydromechanical power output shaft maximum impact are listed in Table 5. The clutches in group 1 and group 2 have much more effect on evaluation index III than that in group 3 , so the scheme $\mathrm{B}_{3} \mathrm{~A}_{3} \mathrm{C}_{3}$ can be replaced by the scheme $\mathrm{B}_{3} \mathrm{~A}_{3}$. The interval of index III is changed from $[9.19,54.08]$ (all schemes) to [9.19, 25.50] (scheme $\mathrm{B}_{3} \mathrm{~A}_{3}$ ).

(4) Output Shaft Maximum Impact. The simulation parameters of output shaft maximum impact are listed in Table 6. The clutches in group 1 and group 3 have much more effect 
TABLE 5: Range analysis table of hydromechanical power output shaft maximum impact based on the shifting time.

\begin{tabular}{|c|c|c|c|c|c|c|}
\hline & Factor & $\mathrm{A}$ & B & $\mathrm{C}$ & $\mathrm{D}$ & \multirow{2}{*}{$\begin{array}{l}\text { Evaluation } \\
\text { index III }\end{array}$} \\
\hline & Column & 1 & 2 & 3 & 4 & \\
\hline \multirow{9}{*}{$\begin{array}{l}\text { Test } \\
\text { schemes }\end{array}$} & Test 1 & 1 & 1 & 1 & 1 & 49.14 \\
\hline & Test 2 & 1 & 2 & 2 & 2 & 37.46 \\
\hline & Test 3 & 1 & 3 & 3 & 3 & 36.80 \\
\hline & Test 4 & 2 & 1 & 2 & 3 & 46.74 \\
\hline & Test 5 & 2 & 2 & 3 & 1 & 47.73 \\
\hline & Test 6 & 2 & 3 & 1 & 2 & 21.12 \\
\hline & Test 7 & 3 & 1 & 3 & 2 & 18.79 \\
\hline & Test 8 & 3 & 2 & 1 & 3 & 42.76 \\
\hline & Test 9 & 3 & 3 & 2 & 1 & 27.90 \\
\hline \multirow{3}{*}{$\begin{array}{l}\text { Mean } \\
\text { number }\end{array}$} & $K_{1}$ & 41.13 & 38.22 & 37.67 & 41.59 & \multirow{3}{*}{$K=36.49$} \\
\hline & $K_{2}$ & 38.53 & 42.65 & 37.37 & 25.79 & \\
\hline & $K_{3}$ & 29.82 & 28.61 & 34.44 & 42.10 & \\
\hline Range & $R$ & 11.31 & 14.04 & 3.23 & 16.31 & \\
\hline \multicolumn{2}{|c|}{ Optimization scheme } & \multicolumn{5}{|c|}{$\mathrm{B}_{3} \mathrm{~A}_{3} \mathrm{C}_{3}$} \\
\hline
\end{tabular}

TABLE 6: Range analysis table of output shaft maximum impact based on the shifting time.

\begin{tabular}{|c|c|c|c|c|c|c|}
\hline & Factor & $\mathrm{A}$ & B & $\mathrm{C}$ & $\mathrm{D}$ & \multirow{2}{*}{$\begin{array}{l}\text { Evaluation } \\
\text { index IV }\end{array}$} \\
\hline & Column & 1 & 2 & 3 & 4 & \\
\hline \multirow{9}{*}{$\begin{array}{l}\text { Test } \\
\text { schemes }\end{array}$} & Test 1 & 1 & 1 & 1 & 1 & 14.28 \\
\hline & Test 2 & 1 & 2 & 2 & 2 & 12.36 \\
\hline & Test 3 & 1 & 3 & 3 & 3 & 18.43 \\
\hline & Test 4 & 2 & 1 & 2 & 3 & 12.50 \\
\hline & Test 5 & 2 & 2 & 3 & 1 & 17.93 \\
\hline & Test 6 & 2 & 3 & 1 & 2 & 18.15 \\
\hline & Test 7 & 3 & 1 & 3 & 2 & 12.63 \\
\hline & Test 8 & 3 & 2 & 1 & 3 & 8.27 \\
\hline & Test 9 & 3 & 3 & 2 & 1 & 5.85 \\
\hline \multirow{3}{*}{$\begin{array}{l}\text { Mean } \\
\text { number }\end{array}$} & $K_{1}$ & 15.02 & 13.14 & 13.57 & 12.69 & \multirow{3}{*}{$K=13.83$} \\
\hline & $K_{2}$ & 16.19 & 12.85 & 10.24 & 14.38 & \\
\hline & $K_{3}$ & 8.92 & 14.14 & 16.33 & 13.07 & \\
\hline Range & $R$ & 7.27 & 1.29 & 6.09 & 1.69 & \\
\hline \multicolumn{2}{|c|}{ Optimization scheme } & \multicolumn{5}{|c|}{$\mathrm{A}_{3} \mathrm{C}_{2} \mathrm{~B}_{2}$} \\
\hline
\end{tabular}

on evaluation index IV than that in group 2, so the scheme $\mathrm{A}_{3} \mathrm{C}_{2} \mathrm{~B}_{2}$ can be replaced by the scheme $\mathrm{A}_{3} \mathrm{C}_{2}$. The interval of index IV is changed from $[4.56,21.02]$ (all schemes) to [4.56, 6.25] (scheme $\mathrm{B}_{3} \mathrm{~A}_{3}$ ).

According to the analyses above, the clutches in group 3 should be switched earlier than that in group 1 and group 2. That is to say, we should switch the clutches of shifting mechanism at first and then control the clutches of planetary gear mechanism.

3.3.2. Switching Strategy of Clutches in Group 3. Single factor loading test should be used to analyze switching strategy of clutches in group 3. The switching time of clutches is shown in Table 7.

Shifting quality simulation results of clutches in group 3 are shown in Figure 12.
The output shaft lowest speed, respectively, reaches $1066.27 \mathrm{r} / \mathrm{min}, 1021.80 \mathrm{r} / \mathrm{min}$, and $1059.50 \mathrm{r} / \mathrm{min}$ in $10.94 \mathrm{~s}$, $11.05 \mathrm{~s}$, and $10.85 \mathrm{~s}$, so the output shaft speed drop amplitude is, respectively, $7.15 \%, 6.39 \%$, and $7.74 \%$, showing that switching time has little effect on evaluation index I.

The output shaft maximum torque, respectively, reaches 187.90 Nm, $189.59 \mathrm{Nm}$, and $203.11 \mathrm{Nm}$ in $11.21 \mathrm{~s}, 11.35 \mathrm{~s}$, and $11.09 \mathrm{~s}$, so the output shaft dynamic load coefficient is, respectively, $1.88,1.89$, and 2.03 , showing that there is little difference on evaluation index II when the switching time of $C_{6}$ is not later than that of $C_{7}$.

The hydromechanical power output shaft maximum impact, respectively, reaches $27.40,19.76$, and 20.32 in $11.13 \mathrm{~s}$, $11.13 \mathrm{~s}$, and $11.09 \mathrm{~s}$, showing that evaluation index III has excellent performance when the switching time of $C_{6}$ is not earlier than that of $C_{7}$. 

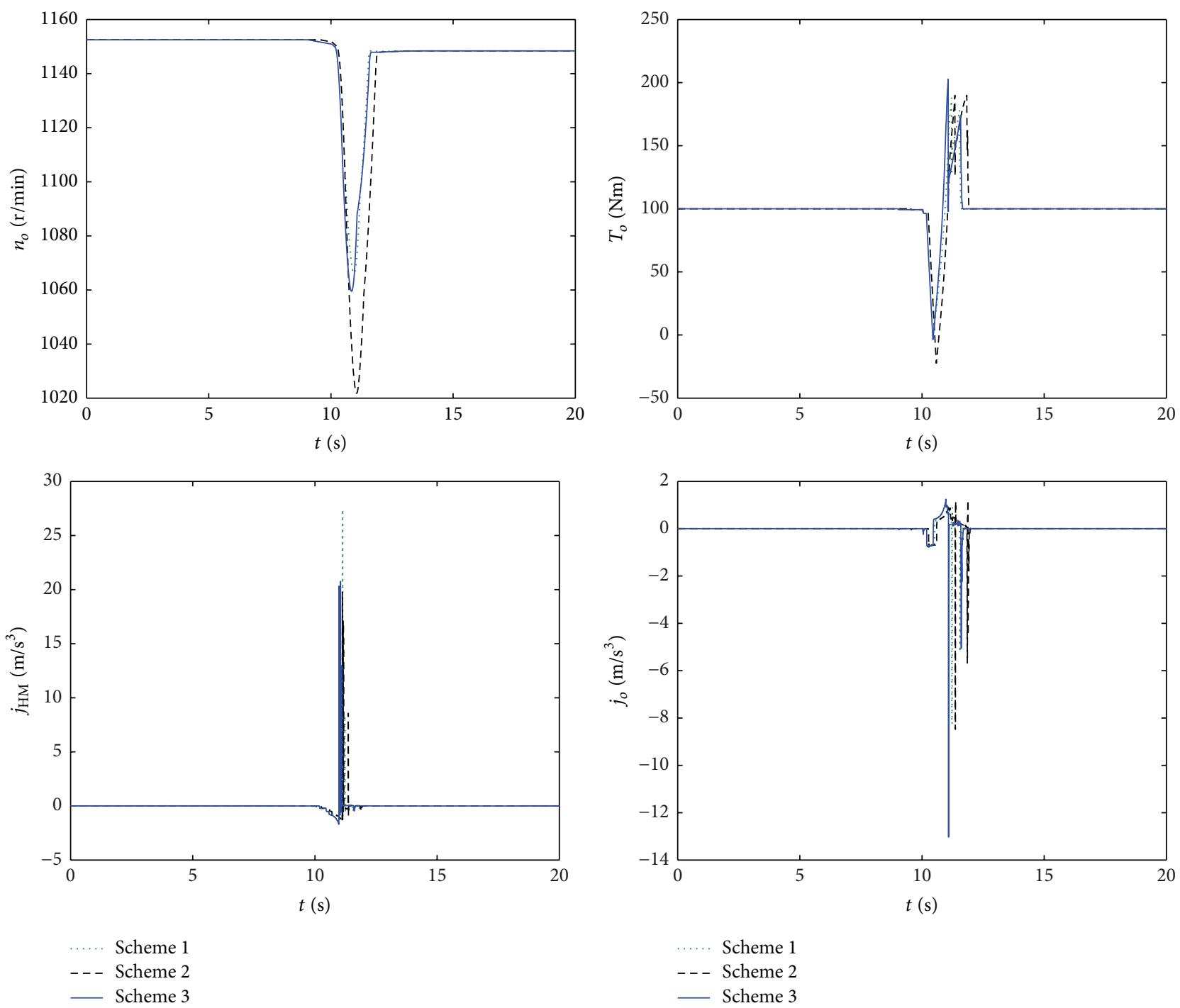

FIGURE 12: Shifting quality simulation results of clutches in group 3.

The output shaft maximum impact, respectively, reaches $8.24,8.48$, and 13.03 in $11.23 \mathrm{~s}, 11.36 \mathrm{~s}$, and $10.99 \mathrm{~s}$, showing that evaluation index IV has excellent performance when the switching time of $C_{6}$ is not later than that of $C_{7}$.

According to the analyses above, the control strategy of clutches in group 3 is that clutches $C_{6}$ and $C_{7}$ are switched at the same time.

\subsubsection{Switching Strategy of Clutches in Group 1 and Group} 2. Range analysis should be used to analyze the switching strategy of clutches in group 1 and group 2. The switching data of clutches are shown in Table 8.

According to the $\mathrm{L}_{9}\left(3^{4}\right)$ orthogonal tables related to the evaluation indices of shifting quality, the range analysis conclusions for the clutches of planetary gear mechanism based on the shifting time are shown in Table 9.

According to the simulation conclusions in Table 9, the scheme $A_{3} B_{3} C_{3} D_{2(3)}$ can be replaced by the scheme $A_{3} B_{3} C_{3}$ for evaluation index $I$, the interval of which is changed from $[3.58 \%, 11.02 \%]$ (all schemes) to [3.58\%, 4.14\%] (scheme
TABLE 7: The switching time of clutches (switching strategy of clutches in group 3).

\begin{tabular}{ccc}
\hline & Disengagement time & Engagement time \\
\hline $\begin{array}{l}\text { Assumed } \\
\text { conditions } \\
\text { Group 1 }\end{array}$ & $C_{1}, C_{3}(10.00 \mathrm{~s})$ & \\
Group 2 & & $C_{2}, C_{4}(10.00 \mathrm{~s})$ \\
Group 3 & & \\
Scheme 1 & $C_{6}(9.00 \mathrm{~s})$ & $C_{7}(9.50 \mathrm{~s})$ \\
Scheme 2 & $C_{6}(9.50 \mathrm{~s})$ & $C_{7}(9.50 \mathrm{~s})$ \\
Scheme 3 & $C_{6}(9.50 \mathrm{~s})$ & $C_{7}(9.00 \mathrm{~s})$ \\
\hline
\end{tabular}

$A_{3} B_{3} C_{3}$ ); the scheme $A_{1} C_{1} B_{1} D_{1}$ can be replaced by the scheme $A_{1} C_{1} B_{1}$ for evaluation index II, the interval of which is changed from $[1.91,2.68]$ (all schemes) to [1.91, 2.17] (scheme $A_{1} C_{1} B_{1}$ ); the scheme $D_{3} C_{1} B_{1} A_{1}$ can be replaced by the scheme $D_{3} C_{1} B_{1}$ for evaluation index III, the interval 


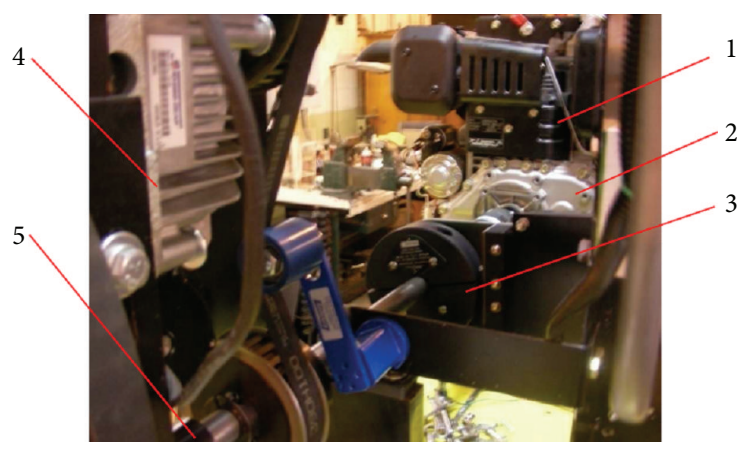

FIGURE 13: Mechanical transmission system. (1) Valves assembly, (2) engine, (3) torque-speed transducer, (4) HMCVT, and (5) dynamometer.

TABLE 8: The switching data of clutches (switching strategy of clutches in group 1 and group 2).

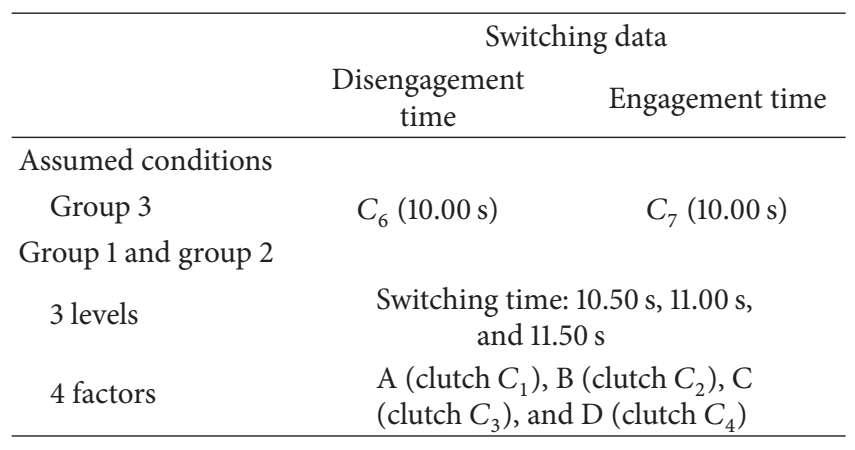

of which is changed from $[11.70,39.43]$ (all schemes) to $[11.70,13.64]$ (scheme $\mathrm{D}_{3} \mathrm{C}_{1} \mathrm{~B}_{1}$ ); the scheme $\mathrm{A}_{1} \mathrm{C}_{1} \mathrm{~B}_{2} \mathrm{D}_{3}$ can be replaced by the scheme $A_{1} C_{1} B_{2}$ for evaluation index $I V$, the interval of which is changed from $[-3.99,53.55]$ (all schemes) to $[-3.99,2.56]$ (scheme $A_{1} C_{1} B_{2}$ ).

In order to obtain good shifting strategy based on the shifting time from $\mathrm{F}_{2}(\mathrm{~N})$ to $\mathrm{F}_{3}(\mathrm{P})$, the switching sequence of clutches is as follows: group $3 \rightarrow$ group $1 \rightarrow$ group 2 .

3.4. Simulation Analysis of Shifting Strategy $\left(F(H) \rightarrow F_{1}(P)\right)$. Range analysis also should be used to analyze the control strategy of clutches in the shifting process from $\mathrm{F}(\mathrm{H})$ to $\mathrm{F}_{1}(\mathrm{P})$. Factors $\mathrm{A}, \mathrm{B}, \mathrm{C}$, and $\mathrm{D}$, respectively, represent clutches $\mathrm{C}_{2}$, $C_{4}, C_{5}$, and $C_{8}$. Levels 1,2 , and 3, respectively, represent the different switching time of clutches (9.50, 10.00, and $10.50 \mathrm{~s})$.

The range analysis conclusions for clutches from $\mathrm{F}(\mathrm{H})$ to $\mathrm{F}_{1}(\mathrm{P})$ are shown in Table 10.

The simulation condition can be expressed as follows: engine rotational speed is $1200 \mathrm{r} / \mathrm{min}$; load torque is $100 \mathrm{Nm}$; main circuit pressure is $40 \mathrm{bar}$; speed valve flow rate is $4 \mathrm{~L} / \mathrm{min}$.

According to the simulation conclusions in Table 10, the scheme $A_{1} C_{3} B_{1} D_{2}$ can be replaced by the scheme $A_{1} C_{3}$ for evaluation index $\mathrm{I}$, the interval of which is changed from [8.40\%, 69.43\%] (all schemes) to [8.40\%, 22.89\%] (scheme $\mathrm{A}_{1} \mathrm{C}_{3}$ ); the scheme $\mathrm{D}_{1} \mathrm{~B}_{1} \mathrm{C}_{3} \mathrm{~A}_{2}$ can be replaced by the scheme $\mathrm{D}_{1} \mathrm{~B}_{1}$ for evaluation index II, the interval of which is changed from $[2.25,3.98]$ (all schemes) to [2.25, 2.82] (scheme
$\mathrm{D}_{1} \mathrm{~B}_{1}$ ); the scheme $\mathrm{B}_{2} \mathrm{D}_{1} \mathrm{~A}_{3} \mathrm{C}_{1}$ can be replaced by the scheme $\mathrm{B}_{2} \mathrm{D}_{1} \mathrm{~A}_{3}$ for evaluation index III, the interval of which is changed from [7.94, 35.12] (all schemes) to [7.94, 11.00] (scheme $\mathrm{B}_{2} \mathrm{D}_{1} \mathrm{~A}_{3}$ ); the scheme $\mathrm{B}_{2} \mathrm{~A}_{1} \mathrm{D}_{3} \mathrm{C}_{2}$ can be replaced by the scheme $\mathrm{B}_{2} \mathrm{~A}_{1}$ for evaluation index IV, the interval of which is changed from $[25.05,69.64]$ (all schemes) to [25.05, 32.05] (scheme $\mathrm{B}_{2} \mathrm{~A}_{1}$ ).

In order to obtain good shifting strategy based on the shifting time from $\mathrm{F}(\mathrm{H})$ to $\mathrm{F}_{1}(\mathrm{P})$, the switching sequence of clutches is $\mathrm{C}_{2}, \mathrm{C}_{8} \rightarrow \mathrm{C}_{4} \rightarrow \mathrm{C}_{5}$.

\section{Test Verification of Shifting Strategy}

4.1. HMCVT Test Bench. HMCVT test bench includes two parts: (1) mechanical transmission system, (2) computer measurement and control system.

Mechanical transmission system, which is shown in Figure 13, mainly includes valve assembly, engine, torquespeed transducer, HMCVT, and dynamometer [26, 35-37].

Computer measurement and control system is composed of upper machine (PC) and two lower machines (MCU). The upper machine exchanges data with data acquisition cards and serial ports, and the lower machines perform data acquisition. The CAN interface cards realize the communication between the upper machine and the lower machines, and the Labview is used as the software development platform. The computer measurement and control system is shown in Figure 14.

4.2. Test Verification of Shifting Strategy $\left(F_{2}(N) \rightarrow F_{3}(P)\right)$. The test verification of control strategy based on shifting time from $F_{2}(N)$ to $F_{3}(P)$ was divided into 3 groups, which are shown in Table 11.

According to Table 11, the test curves are shown in Figure 15.

According to the test curves in Figure 13, the output shaft lowest rotational speed is, respectively, $677 \mathrm{r} / \mathrm{min}, 836 \mathrm{r} / \mathrm{min}$, and $1091 \mathrm{r} / \mathrm{min}$ in tests 1,2 , and 3 , and the corresponding output shaft speed drop amplitude is, respectively, $41.03 \%$, $27.18 \%$, and $4.97 \%$; the output shaft maximum torque is, respectively, $286 \mathrm{Nm}, 275 \mathrm{Nm}$, and $237 \mathrm{Nm}$, and the corresponding output shaft dynamic load coefficient is, respectively, 2.86, 2.75, and 2.37; the hydromechanical power output shaft maximum impact, respectively, reaches $26.81,26.90$, and 20.13 in $12.52 \mathrm{~s}, 10.81 \mathrm{~s}$, and $11.22 \mathrm{~s}$; the output shaft maximum 
TABLE 9: Range analysis conclusions for the clutches of planetary gear mechanism based on the shifting time $\left(F_{2}(N) \rightarrow F_{3}(P)\right)$.

\begin{tabular}{|c|c|c|c|c|c|}
\hline \multirow{2}{*}{$\begin{array}{l}\text { Evaluation } \\
\text { indices }\end{array}$} & \multicolumn{4}{|c|}{ Factors } & \multirow{2}{*}{ Optimization schemes } \\
\hline & $\mathrm{A}$ & B & $\mathrm{C}$ & $\mathrm{D}$ & \\
\hline I & $3.20 \%$ & $1.87 \%$ & $1.81 \%$ & $0.56 \%$ & $\mathrm{~A}_{3} \mathrm{~B}_{3} \mathrm{C}_{3} \mathrm{D}_{2(3)}$ \\
\hline II & 0.29 & 0.19 & 0.22 & 0.07 & $\mathrm{~A}_{1} \mathrm{C}_{1} \mathrm{~B}_{1} \mathrm{D}_{1}$ \\
\hline III & 1.94 & 6.63 & 9.51 & 9.65 & $\mathrm{D}_{3} \mathrm{C}_{1} \mathrm{~B}_{1} \mathrm{~A}_{1}$ \\
\hline IV & 24.27 & 12.14 & 14.58 & 6.55 & $\mathrm{~A}_{1} \mathrm{C}_{1} \mathrm{~B}_{2} \mathrm{D}_{3}$ \\
\hline
\end{tabular}

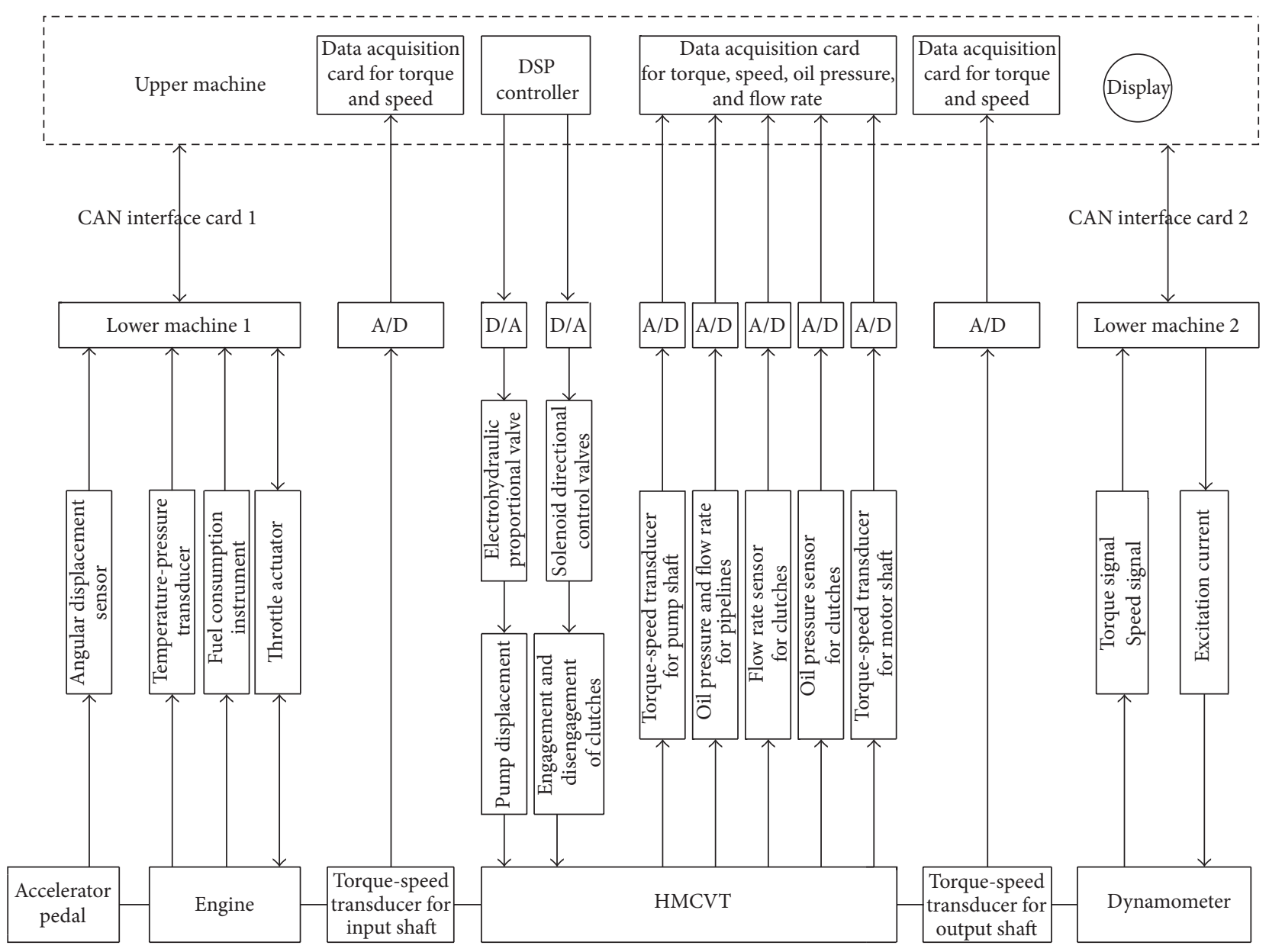

FIGURE 14: Computer measurement and control system.

impact, respectively, reaches $11.80,11.94$, and 18.15 in $12.52 \mathrm{~s}$, $10.81 \mathrm{~s}$, and $11.22 \mathrm{~s}$; the shifting time is, respectively, $4.58 \mathrm{~s}$, $3.25 \mathrm{~s}$, and $1.83 \mathrm{~s}$. So the optimal comprehensive performance of shifting process from $\mathrm{F}_{2}(\mathrm{~N})$ to $\mathrm{F}_{3}(\mathrm{P})$ can be obtained in test 3 , which can verify the correctness of simulation results.

4.3. Test Verification of Shifting Strategy $\left(F(H) \rightarrow F_{1}(P)\right)$. The test verification of control strategy based on shifting time from $\mathrm{F}(\mathrm{H})$ to $\mathrm{F}_{1}(\mathrm{P})$ was divided into 3 groups, which are shown in Table 12.

According to Table 12, the test curves are shown in Figure 16.

According to the test curves in Figure 14, the output shaft lowest rotational speed is, respectively, $144 \mathrm{r} / \mathrm{min}, 162 \mathrm{r} / \mathrm{min}$, and $259 \mathrm{r} / \mathrm{min}$ in tests 1,2 , and 3 , and the corresponding output shaft speed drop amplitude is, respectively, 50.85\%, $44.71 \%$, and $11.60 \%$; the output shaft maximum torque is, respectively, $359 \mathrm{Nm}, 333 \mathrm{Nm}$, and $235 \mathrm{Nm}$, and the corresponding output shaft dynamic load coefficient is, respectively, 3.59, 3.33, and 2.35; the hydromechanical power output shaft maximum impact, respectively, reaches $12.29,16.67$, and 25.05 in $10.98 \mathrm{~s}, 11.78 \mathrm{~s}$, and $11.11 \mathrm{~s}$; the output shaft maximum impact, respectively, reaches $60.42,56.37$, and 23.51 in $10.99 \mathrm{~s}$, $11.39 \mathrm{~s}$, and $11.06 \mathrm{~s}$; the shifting time is, respectively, $1.95 \mathrm{~s}$, $2.26 \mathrm{~s}$, and $1.67 \mathrm{~s}$. So the optimal comprehensive performance of shifting process from $\mathrm{F}(\mathrm{H})$ to $\mathrm{F}_{1}(\mathrm{P})$ can be obtained in test 3 , which can verify the correctness of simulation results. 
TABLE 10: Range analysis conclusions for clutches based on the shifting time $\left(\mathrm{F}(\mathrm{H}) \rightarrow \mathrm{F}_{1}(\mathrm{P})\right)$.

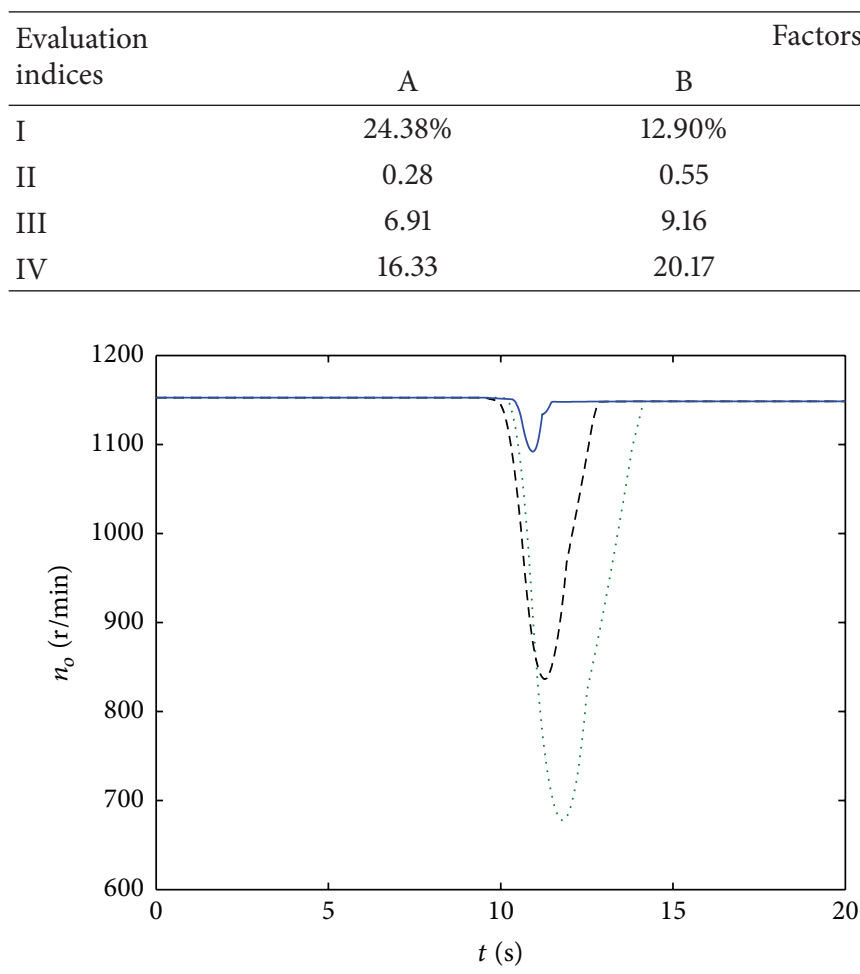

Optimization schemes

\begin{tabular}{lccccc}
$\begin{array}{l}\text { Evaluation } \\
\text { indices }\end{array}$ & $\mathrm{A}$ & $\mathrm{B}$ & Factors & $\mathrm{C}$ & Optimization schemes \\
\hline I & $24.38 \%$ & $12.90 \%$ & $21.26 \%$ & $2.59 \%$ & $\mathrm{~A}_{1} \mathrm{C}_{3} \mathrm{~B}_{1} \mathrm{D}_{2}$ \\
II & 0.28 & 0.55 & 0.29 & 0.61 & $\mathrm{D}_{1} \mathrm{~B}_{1} \mathrm{C}_{3} \mathrm{~A}_{2}$ \\
III & 6.91 & 9.16 & 3.06 & 8.05 & $\mathrm{~B}_{2} \mathrm{D}_{1} \mathrm{~A}_{3} \mathrm{C}_{1}$ \\
IV & 16.33 & 20.17 & 1.59 & 6.50 & $\mathrm{~B}_{2} \mathrm{~A}_{1} \mathrm{D}_{3} \mathrm{C}_{2}$ \\
\hline
\end{tabular}
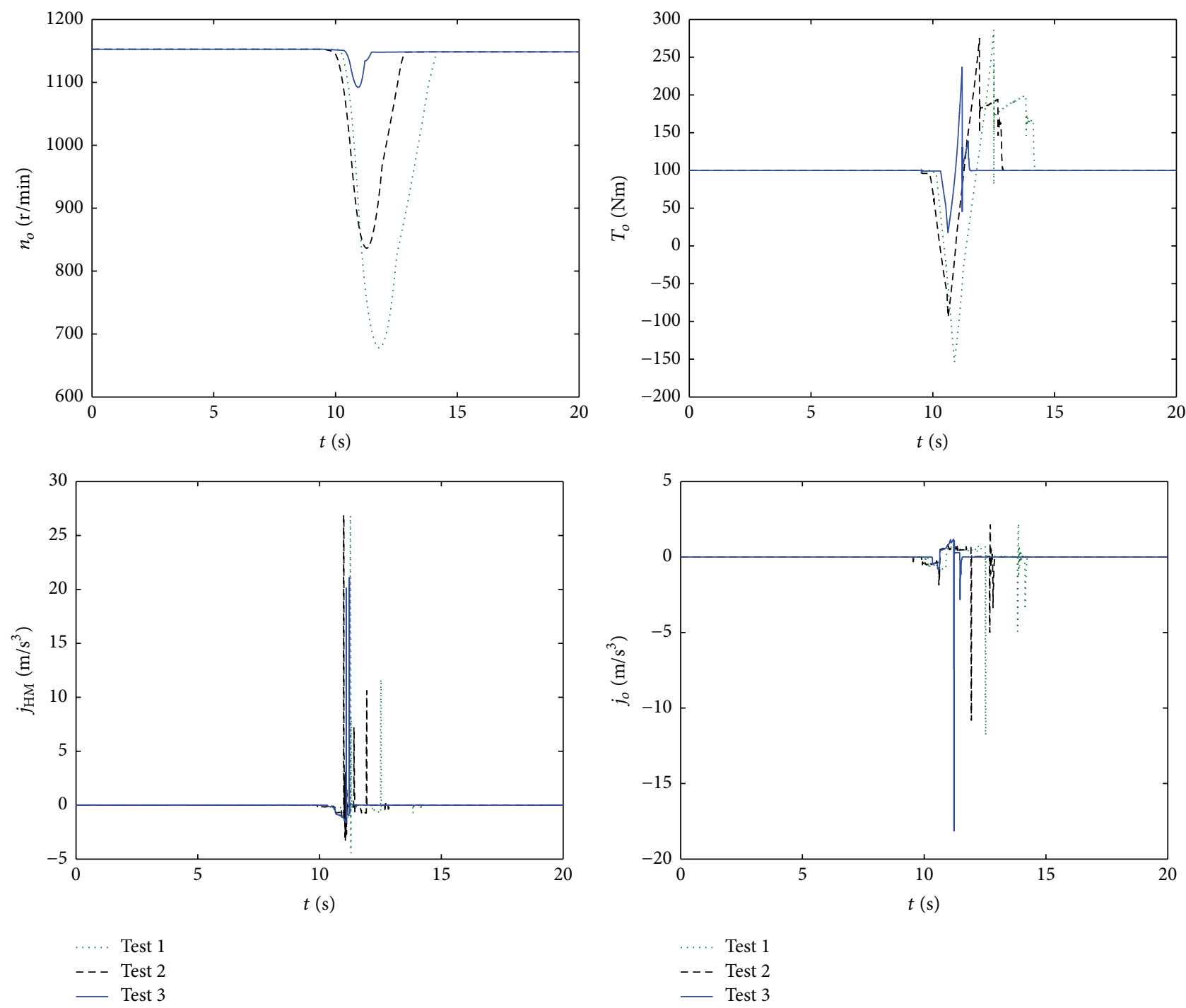

Figure 15: Test curves of shifting strategy $\left(\mathrm{F}_{2}(\mathrm{~N}) \rightarrow \mathrm{F}_{3}(\mathrm{P})\right)$.

TABLE 11: The switching time of clutches $\left(\mathrm{F}_{2}(\mathrm{~N}) \rightarrow \mathrm{F}_{3}(\mathrm{P})\right)$.

\begin{tabular}{lccc}
\hline & \multicolumn{3}{c}{ Switching time } \\
& $9.50 \mathrm{~s}$ & $10.00 \mathrm{~s}$ & $10.50 \mathrm{~s}$ \\
\hline Test 1 & Group 1 & Group 2 & Group 3 \\
Test 2 & Group 2 & Group 3 & Group 1 \\
Test 3 & Group 3 & Group 1 & Group 2 \\
\hline
\end{tabular}

TABLE 12: The switching time of clutches $\left(\mathrm{F}(\mathrm{H}) \rightarrow \mathrm{F}_{1}(\mathrm{P})\right)$.

\begin{tabular}{lccc}
\hline & \multicolumn{3}{c}{ Switching time } \\
& $9.50 \mathrm{~s}$ & $10.00 \mathrm{~s}$ & $10.50 \mathrm{~s}$ \\
\hline Test 1 & $C_{5}$ & $C_{2}, C_{8}$ & $C_{4}$ \\
Test 2 & $C_{4}$ & $C_{5}$ & $C_{2}, C_{8}$ \\
Test 3 & $C_{2}, C_{8}$ & $C_{4}$ & $C_{5}$ \\
\hline
\end{tabular}



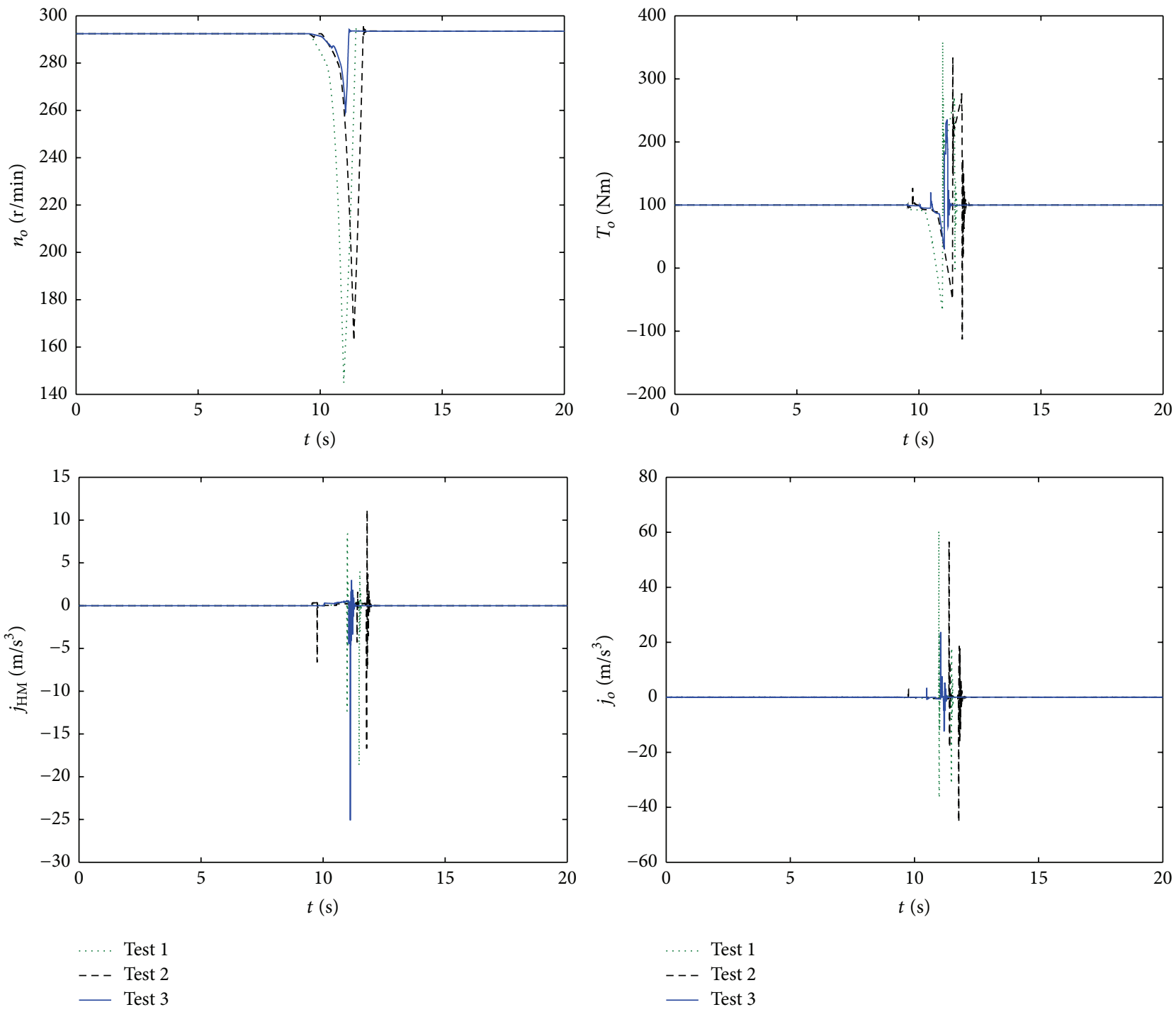

Figure 16: Test curves of shifting strategy $\left(\mathrm{F}(\mathrm{H}) \rightarrow \mathrm{F}_{1}(\mathrm{P})\right)$.

\section{Conclusions}

(1) Shifting quality can be improved greatly by optimizing the shifting time of HMCVT involving multigroup clutches.

(2) The shifting process from $\mathrm{F}(\mathrm{H})$ to $\mathrm{F}_{1}(\mathrm{P})$ and the shifting process from $\mathrm{F}_{j}(\mathrm{~N})$ to $\mathrm{F}_{j+1}(\mathrm{P})$, which play decisive roles of improving the shifting quality during the continuous shifting process, are the typical working conditions.

(3) According to the simulation analysis and test research on the typical working conditions, the control strategy of shifting process from the positive transmission of hydromechanical ranges to the negative transmission of hydromechanical ranges is switching the clutches of shifting mechanism firstly and then disengaging a group of clutches of planetary gear mechanism and engaging another group of clutches of planetary gear mechanism lastly; the control strategy of shifting process from the hydraulic range to the hydromechanical range is switching the clutches of hydraulic shifting mechanism and planetary gear mechanism at first and then engaging the clutch of shifting mechanism.

\section{Nomenclature}

$T_{1}$ : Input shaft torque

$J_{1}:$ Input shaft equivalent rotational inertia

$\omega_{2}$ : Hydromechanical power output shaft rotational speed

$T_{3}$ : Output shaft torque

$J_{3}$ : Output shaft equivalent rotational inertia

$\omega_{P}$ : Pump shaft rotational speed

$T_{M}$ : Motor shaft torque

$J_{M}$ : Motor shaft equivalent rotational inertia

$\omega_{s}$ : Sun gear shaft rotational speed

$T_{r}$ : Ring gear torque

$J_{r}$ : Ring gear equivalent rotational inertia

$\omega_{c}:$ Planetary carrier rotational speed

$T_{c i}$ : Clutch $i$ torque

$J_{c i}$ : Clutch $i$ equivalent rotational inertia

$T_{\mathrm{EN}}$ : Equivalent negative torque

$J_{E}$ : Equivalent rotational inertia

$e: \quad$ Displacement ratio 
$P_{h}: \quad$ High pressure of hydraulic system

$D_{P}: \quad$ Pump displacement

$D_{M \text { max }}$ : Motor maximum displacement

$\beta_{e}$ : $\quad$ Hydraulic oil bulk modulus

$R_{\mathrm{Ci2}}$ : Clutch $i$ friction surface inner diameter

$\omega_{\mathrm{C} i 2}$ : Clutch $i$ driven disk rotational speed

$\mu_{r C i}: \quad$ Clutch $i$ sliding friction coefficient

$p_{c i \text { max }}$ : Clutch $i$ maximum hydraulic pressure

$\kappa_{i \text { on }}: \quad$ Variation rate of engaging pressure for clutch $i$

$C_{C i}: \quad$ TCU control command

$C_{C i}=1$ : Clutch $i$ engaging signal

$n_{o \text { min }}$ : Output shaft minimum rotational speed

$\gamma: \quad$ Dynamic load coefficient

$\bar{T}_{o}$ : Output shaft stable torque

v: $\quad$ Tractor velocity

$\omega_{1}$ : Input shaft rotational speed

$T_{2}$ : $\quad$ Hydromechanical power output shaft torque

$J_{2}$ : $\quad$ Hydromechanical power output shaft equivalent rotational inertia

$\omega_{3}: \quad$ Output shaft rotational speed

$T_{P}$ : $\quad$ Pump shaft torque

$J_{P}: \quad$ Pump shaft equivalent rotational inertia

$\omega_{M}: \quad$ Motor shaft rotational speed

$T_{s}$ : $\quad$ Sun gear shaft torque

$J_{s}: \quad$ Sun gear shaft equivalent rotational inertia

$\omega_{r}$ : Ring gear rotational speed

$T_{c}$ : $\quad$ Planetary carrier torque

$J_{c}: \quad$ Planetary carrier equivalent rotational inertia

$\omega_{C i}: \quad$ Clutch $i$ rotational speed

$T_{\mathrm{EP}}$ : Equivalent positive torque

$\omega_{E}: \quad$ Equivalent rotational speed

$i_{i}$ : $\quad$ Gear $i$ transmission ratio

$k$ : $\quad$ Planetary gear characteristic parameter

$P_{l}$ : $\quad$ Low pressure of hydraulic system

$I_{P}$ : $\quad$ Control current

$V: \quad$ Hydraulic system working volume

$R_{\mathrm{Ci1}}$ : $\quad$ Clutch $i$ friction surface outer diameter

$\omega_{C i 1}$ : Clutch $i$ driving disk rotational speed

$Z_{C i}$ : Clutch $i$ number of friction surfaces

$p_{c i}: \quad$ Clutch $i$ hydraulic pressure

$\tau$ : $\quad$ Delay time

$\kappa_{i \text { off }}$ : Variation rate of disengaging pressure for clutch $i$

$C_{C i}=0$ : Clutch $i$ disengaging signal

$\delta: \quad$ Output shaft speed drop amplitude

$\bar{n}_{o}$ : Output shaft stable rotational speed

$T_{o \text { max }}$ : Output shaft maximum torque

$j_{\mathrm{HM}} / j_{o}$ : Hydromechanical power output shaft/output shaft impact

$\beta$ : $\quad$ Angular acceleration.

\section{Conflict of Interests}

The authors declare that there is no conflict of interests regarding the publication of this paper.

\section{Acknowledgments}

This paper is financially supported by National Natural Science Foundation Project (51575001) and Scientific Research Innovation Project of Jiangsu University (KYXX-0008).

\section{References}

[1] K. Th. Renius, "Continuously variable tractor transmissions," ASAE Publication 913C305, 2005.

[2] G. Mantriota, "Performances of a series infinitely variable transmission with type I power flow," Mechanism and Machine Theory, vol. 37, no. 6, pp. 579-597, 2002.

[3] A. Rossetti and A. MacOr, "Multi-objective optimization of hydro-mechanical power split transmissions," Mechanism and Machine Theory, vol. 62, pp. 112-128, 2013.

[4] A. Macor and A. Rossetti, "Fuel consumption reduction in urban buses by using power split transmissions," Energy Conversion and Management, vol. 71, pp. 159-171, 2013.

[5] R. Pfiffner, L. Guzzella, and C. H. Onder, "Fuel-optimal control of CVT powertrains," Control Engineering Practice, vol. 11, no. 3, pp. 329-336, 2003.

[6] Z. Farkas and G. Kerényi, "Power flows and efficiency analysis of out- and input coupled IVT," Periodica Polytechnica, vol. 53, no. 2, pp. 61-68, 2009.

[7] P. Linares, V. Méndez, and H. Catalán, "Design parameters for continuously variable power-split transmissions using planetaries with 3 active shafts," Journal of Terramechanics, vol. 47, no. 5, pp. 323-335, 2010.

[8] A. K. Gupta and C. P. Ramanarayanan, "Analysis of circulating power within hybrid electric vehicle transmissions," Mechanism and Machine Theory, vol. 64, pp. 131-143, 2013.

[9] M. I. Ramdan, Optimal design of a hydro-mechanical transmission power split hybrid hydraulic bus [Ph.D. dissertation], University of Minnesota, 2013.

[10] A. MacOr and A. Rossetti, "Optimization of hydro-mechanical power split transmissions," Mechanism and Machine Theory, vol. 46, no. 12, pp. 1901-1919, 2011.

[11] B. Depraetere, G. Pinte, W. Symens, and J. Swevers, "A twolevel iterative learning control scheme for the engagement of wet clutches," Mechatronics, vol. 21, no. 3, pp. 501-508, 2011.

[12] Y. Shihua, W. Chao, and Z. Yincai, "Influencing factors for dynamic characteristics of hydro-mechanical continuously variable transmission," Transactions of the Chinese Society of Agricultural Engineering, vol. 24, no. 2, pp. 33-38, 2008.

[13] X. Guoliang, L. Aibo, and J. Qing, "Research on dynamic characteristics of the hydraulic circuit in shifting of hydromechanical continuously variable transmission," Mechine Tool \& Hydraulics, vol. 39, pp. 97-100, 2011.

[14] S. Iqbal, F. Al-Bender, A. P. Ompusunggu, B. Pluymers, and W. Desmet, "Modeling and analysis of wet friction clutch engagement dynamics," Mechanical Systems and Signal Processing, vol. 60-61, pp. 420-436, 2015.

[15] G. Wang, S. Zhu, L. Shi, H. Tao, and N. Vanthinh, "Experimental optimization on shift control of hydraulic mechanical continuously variable transmission for tractor," Transactions of the Chinese Society of Agricultural Engineering, vol. 29, no. 18, pp. 51-59, 2013.

[16] M. Kulkarni, T. Shim, and Y. Zhang, "Shift dynamics and control of dual-clutch transmissions," Mechanism and Machine Theory, vol. 42, no. 2, pp. 168-182, 2007. 
[17] E. Galvagno, M. Velardocchia, and A. Vigliani, "Dynamic and kinematic model of a dual clutch transmission," Mechanism and Machine Theory, vol. 46, no. 6, pp. 794-805, 2011.

[18] P. D. Walker and N. Zhang, "Modelling of dual clutch transmission equipped powertrains for shift transient simulations," Mechanism and Machine Theory, vol. 60, pp. 47-59, 2013.

[19] P. D. Walker and N. Zhang, "Active damping of transient vibration in dual clutch transmission equipped powertrains: a comparison of conventional and hybrid electric vehicles," Mechanism and Machine Theory, vol. 77, pp. 1-12, 2014.

[20] A. P. Ompusunggu, P. Sas, and H. Van Brussel, "Modeling and simulation of the engagement dynamics of a wet friction clutch system subjected to degradation: an application to condition monitoring and prognostics," Mechatronics, vol. 23, no. 6, pp. 700-712, 2013.

[21] X. Zhou, P. Walker, N. Zhang, B. Zhu, and J. Ruan, "Numerical and experimental investigation of drag torque in a two-speed dual clutch transmission," Mechanism and Machine Theory, vol. 79, pp. 46-63, 2014.

[22] D. C. Kim, K. U. Kim, Y. J. Park, and J. Y. Huh, "Analysis of shifting performance of power shuttle transmission," Journal of Terramechanics, vol. 44, no. 1, pp. 111-122, 2007.

[23] F. Meng, G. Tao, and H. Chen, "Smooth shift control of an automatic transmission for heavy-duty vehicles," Neurocomputing, vol. 159, pp. 197-206, 2015.

[24] Z. Zhen, G. Xiang, P. Daoyuan et al., "Design and test analysis of HMCVT," Machine Design and Research, vol. 31, pp. 53-56, 2015.

[25] Z. Yingjun, Study on the control strategy of hydro-mechanical continuously variable transmission of tractor [Ph.D. thesis], Wuhan University of Technology, 2007.

[26] J. J. Oh, S. B. Choi, and J. Kim, "Driveline modeling and estimation of individual clutch torque during gear shifts for dual clutch transmission," Mechatronics, vol. 24, no. 5, pp. 449-463, 2014.

[27] H. Liu, Y. Lin, M. Shi et al., "A novel hydraulic-mechanical hybrid transmission in tidal current turbines," Renewable Energy, vol. 81, pp. 31-42, 2015.

[28] J. R. Gom Ayats, U. Diego-Ayala, and F. F. Artes, “The singular point transition concept: a novel continuously variable transmission comprising planetary gear trains and a variator," Journal of Power Sources, vol. 197, pp. 125-135, 2012.

[29] X.-X. Yin, Y.-G. Lin, W. Li, H.-W. Liu, and Y.-J. Gu, "Adaptive sliding mode back-stepping pitch angle control of a variabledisplacement pump controlled pitch system for wind turbines," ISA Transactions, vol. 58, pp. 629-634, 2015.

[30] H. T. Do, H. G. Park, and K. K. Ahn, "Application of an adaptive fuzzy sliding mode controller in velocity control of a secondary controlled hydrostatic transmission system," Mechatronics, vol. 24, no. 8, pp. 1157-1165, 2014.

[31] F. Meng, H. Chen, T. Zhang et al., "Clutch fill control of an automatic transmission for heavy-duty vehicle applications," Mechanical Systems and Signal Processing, vol. 64-65, pp. 16-28, 2015.

[32] S. Raikwar, V. K. Tewari, S. Mukhopadhyay, C. R. Verma, and M. Sreenivasulu Rao, "Simulation of components of a power shuttle transmission system for an agricultural tractor," Computers and Electronics in Agriculture, vol. 114, pp. 114-124, 2015.

[33] F. Meng, G. Tao, T. Zhang, Y. Hu, and P. Geng, "Optimal shifting control strategy in inertia phase of an automatic transmission for automotive applications," Mechanical Systems and Signal Processing, vol. 60-61, pp. 742-752, 2015.
[34] L. Yulong, L. Xingzhong, L. Weipeng, and Hanyong, "Hydraulic system optimization and dynamic characteristic simulation of double clutch transmission," Procedia Environmental Sciences Part B, vol. 10, pp. 1065-1070, 2011.

[35] J. J. Heber, Instrumented infinitely variable transmission [Ph.D. dissertation], Purdue University, 2011.

[36] A. Dutta, Y. Zhong, B. Depraetere et al., "Model-based and model-free learning strategies for wet clutch control," Mechatronics, vol. 24, no. 8, pp. 1008-1020, 2014.

[37] W. D. Widanage, J. Stoev, A. Van Mulders, J. Schoukens, and G. Pinte, "Nonlinear system-identification of the filling phase of a wet-clutch system," Control Engineering Practice, vol. 19, no. 12, pp. 1506-1516, 2011. 


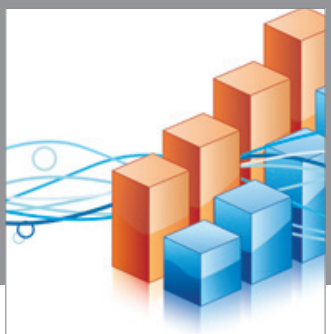

Advances in

Operations Research

vatem alat4

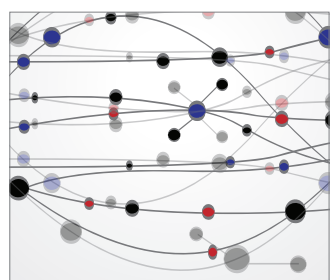

\section{The Scientific} World Journal
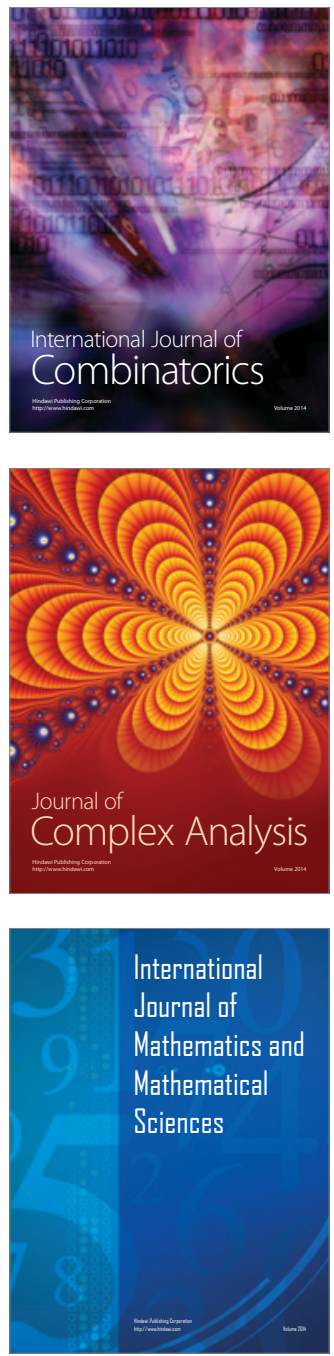
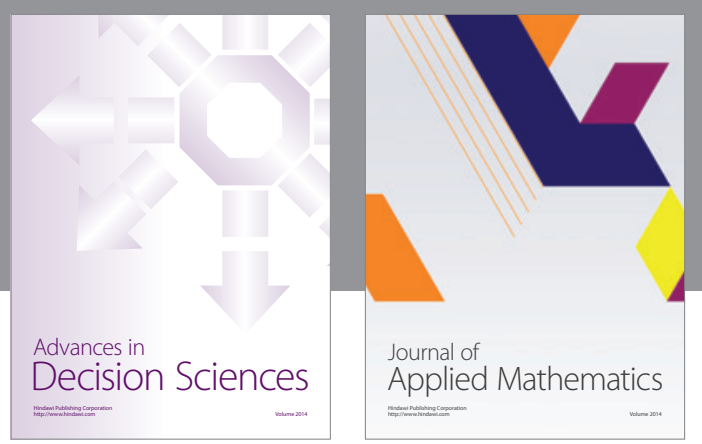

Algebra

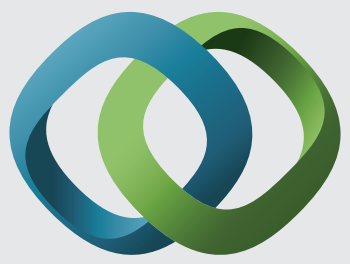

\section{Hindawi}

Submit your manuscripts at

http://www.hindawi.com
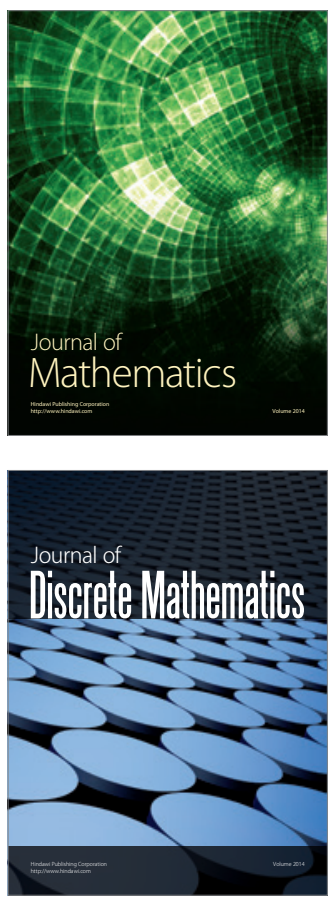

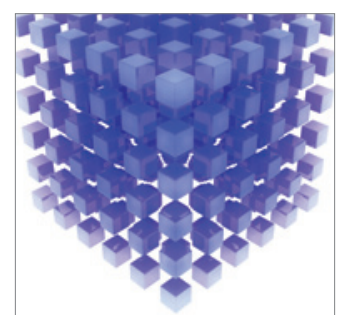

Mathematical Problems in Engineering
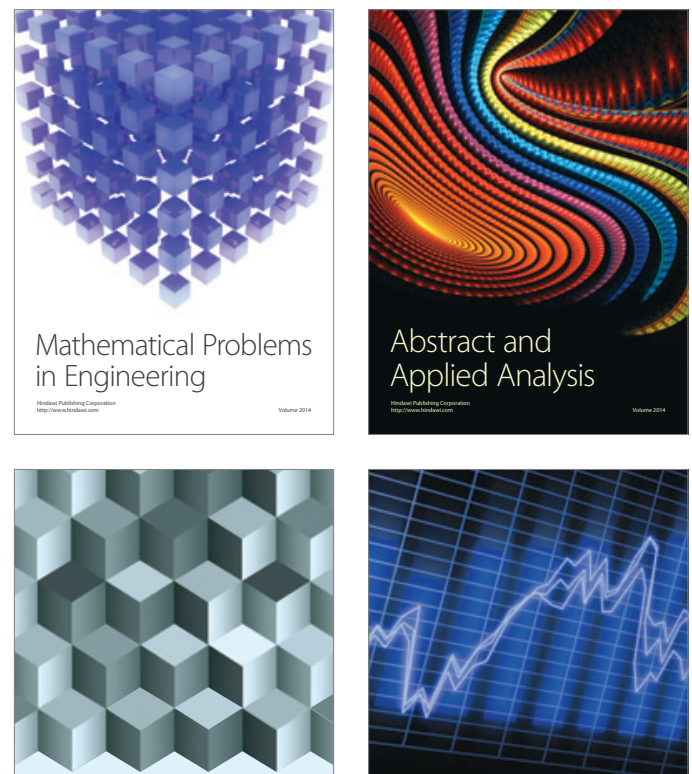

Journal of

Function Spaces

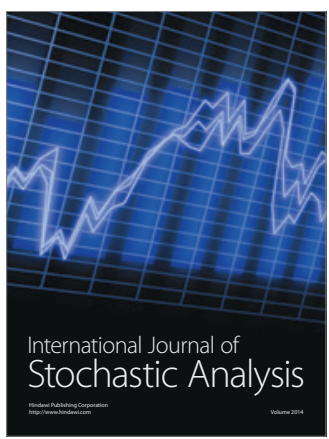

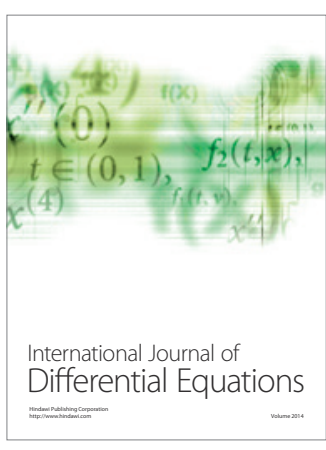
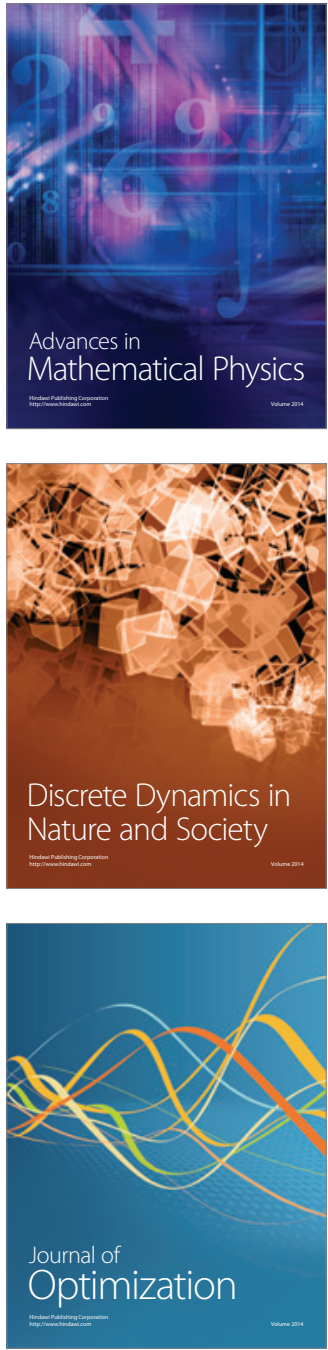